\title{
Old age and fear of crime: cross-national evidence for a decreased impact of neighbourhood disadvantage in older age
}

\author{
Göran Köber ${ }^{1 \star}$ (D), Dietrich Oberwittler ${ }^{2}$ (D) and Rebecca Wickes ${ }^{3}$ (D) \\ ${ }^{1}$ Institute of Medical Biometry and Statistics, Faculty of Medicine and Medical Center, University of \\ Freiburg, Germany, ${ }^{2}$ Independent Research Group Space, Contexts and Crime, Max Planck Institute for the \\ Study of Crime, Security and Law, Freiburg, Germany and ${ }^{3}$ Monash Migration and Inclusion Centre, \\ Monash University, Melbourne, Australia \\ ${ }^{\star}$ Corresponding author. Email: koeber@imbi.uni-freiburg.de
}

(Accepted 12 November 2020; first published online 18 December 2020)

\begin{abstract}
Fear of crime among older people has been a frequent topic in ageing research, criminology and urban studies. The 'environmental docility hypothesis' assumes that older people are more vulnerable to adverse neighbourhood conditions than younger age groups. Yet, few studies have tested this influential hypothesis using samples of respondents covering the complete adult lifespan. Looking at fear of crime, we investigated the person-environment interaction of age and neighbourhood disadvantage, using two independent surveys comprising 12,620 respondents aged 25-90 years residing in 435 neighbourhoods in four cities in Germany and Australia. We used multi-level analysis and cross-level interactions to model age-differential effects of neighbourhood disadvantage on fear. Contrary to the hypothesis, we found a weakening of neighbourhood effects on fear with age. The strong effect of neighbourhood disadvantage on fear of crime dropped by around half from the youngest ( 25 years) to the oldest age ( 90 years) in both countries. Younger people were almost as fearful as older people in the most disadvantaged neighbourhoods, but older people were considerably more fearful than younger ages in better-off neighbourhoods. We found limited empirical support for the assumption that this diminished association between neighbourhood disadvantage and fear can be explained by the stronger neighbourhood attachment of older people. The limitations of the analysis and potential future directions of research are discussed.
\end{abstract}

Keywords: fear of crime; age; neighbourhood; social disadvantage; interaction effects; multi-level modelling

\section{Introduction}

The association between old age and fear of crime has been widely discussed since the ascent of victimisation surveys in the 1960s and 1970s. Early studies

(C) The Author(s), 2020. Published by Cambridge University Press. This is an Open Access article, distributed under the terms of the Creative Commons Attribution-NonCommercial-ShareAlike licence (http://creativecommons.org/licenses/ by-nc-sa/4.0/), which permits non-commercial re-use, distribution, and reproduction in any medium, provided the same Creative Commons licence is included and the original work is properly cited. The written permission of Cambridge University Press must be obtained for commercial re-use. 
(e.g. Goldsmith and Tomas, 1974) suggested that older people are troubled by heightened levels of fear of crime out of proportion with factual victimisation risks, as epitomised in the Time magazine headline 'The elderly: prisoners of fear' (Time, 1976). Subsequent research has partly rebutted this crude notion, added important nuances, and identified psychological and social mechanisms by which old age may stimulate fear of crime (Clemente and Kleiman, 1977; Greve, 1998). A robust finding of extant research is that older people are not generally more worried about victimisation risks but that many feel unsafe walking outdoors/in their residential areas. Consequently, they tend to adapt their daily routines to increasing feelings of unsafety, e.g. by avoiding certain places or being out during dark hours, or by restricting social interaction with neighbours (Greve et al., 2017). Fear of crime is a strongly localised social cognition, and hence the ecological dimension, i.e. urban environments, merits special attention in research on fear of crime of older adults.

Crime and safety-related perceptions and behaviours in urban contexts are relevant topics for several research fields in the social sciences. In criminology and urban sociology, fear of crime is viewed as a part of social processes which may weaken the social fabric of neighbourhoods (Taylor, 1995; Markowitz et al., 2001; Skogan, 2015). In quality-of-life and health research, fear of crime is seen as an impediment to wellbeing and mental health (Lindström et al., 2006; Jackson and Stafford, 2009); and in gerontology and ageing studies, fear of crime is regarded as detrimental to place attachment which is seen as a crucial resource in older age when physical competences and activity spaces become increasingly restricted (De Donder et al., 2012; Wahl et al., 2012). These different research foci notwithstanding, all approaches share a basic feature: neighbourhood-related perceptions and behaviours are fundamentally about person-environment interactions $(\mathrm{P} \times \mathrm{E})$, because the same individual will perceive and react to different urban contexts differently, and different individuals will perceive and react to the same urban context differently (Wikström, 2004; Magnusson and Stattin, 2006). Scholars have investigated at great length both the characteristics of urban neighbourhoods which evoke fear of crime, as well as the individual characteristics of people who report fear of crime, yet the interaction between the individual and the environmental predictors of fear has generally not received the same level of attention. With its predominant focus on the macro-level social processes in communities, criminology and urban sociology have mostly been interested in why residents in some neighbourhoods are on average more fearful than others, and how these neighbourhood-level differences in fear affect the collective social organisation of communities (Robinson et al., 2003; Wyant, 2008; Hinkle, 2013; Barton et al., 2017; Sargeant et al., 2017). Individual differences in these neighbourhoodfocused perceptions, including feelings of unsafety, have largely been ignored (with some exceptions) and are only slowly being included in recent studies.

In contrast, reflecting their cardinal interest in individual wellbeing, gerontology and ageing studies have paid more attention to person-level characteristics that influence safety perceptions as well as the person-level consequences of living in problematic urban environments. Noise, sub-standard housing, concentrated poverty, violence and incivilities are among the environmental factors which may deplete the wellbeing and health of older residents (Annear et al., 2014; Cagney and Cornwell, 
2018). As recent examples, Cagney and Cornwell (2018) found effects of neighbourhood social capital on older residents' wellbeing, Wilson-Genderson and Pruchno (2013) found effects of neighbourhood violent crime on depressive symptoms of older residents and Mendes de Leon et al. (2009) reported a reduced frequency of walking in neighbourhoods with high levels of disorder.

Of course, older adults are not the only demographic group to suffer from lowquality or unsafe urban environments, as an extensive research literature on neighbourhood effects on children and adolescents testifies (Sharkey and Faber, 2014; Chang et al., 2016). However, lifecourse trajectories in older age are typically characterised by reduced social roles and material wealth, decreasing physical strength and increasing health impairments which all may contribute to an increasing vulnerability towards external threats. It was this notion of vulnerability which has led gerontologists to assume that older adults are more susceptible to environmental influences than younger adults. The 'environmental docility hypothesis' (Lawton and Simon, 1968; Lawton, 1990; cf. Schieman, 2009; Wahl and Gerstorf, 2018) can be seen as one of the very few explicit $\mathrm{P} \times \mathrm{E}$ theories of individual wellbeing in ecological contexts. Yet, given the influence of the 'environmental docility hypothesis', surprisingly little empirical evidence has been accumulated to support the notion that older adults are more susceptible to environmental threats than younger age groups (Yen et al., 2009; Wahl et al., 2012). One major reason for this dearth is that research undertaken by gerontologists and ageing scholars in most cases have used specialised samples of restricted age ranges, with the consequence that comparisons of effect sizes across different age groups are rendered impossible. Also, many specialised surveys often do not offer sufficient variability on the ecological level of urban neighbourhoods to ensure enough statistical power for investigating the respondents' reactions to different environmental conditions. As a consequence, a key assumption of the 'environmental docility theory' has remained largely untested: Are older adults more susceptible to adverse environmental conditions than younger age groups?

We use two independent surveys from Germany and Australia comprising 12,620 respondents aged 25-90 years and residing in 435 urban neighbourhoods in four cities to investigate age-specific differences in fear of crime as a reaction to environmental threats, focusing on neighbourhood social disadvantage measured by unemployment rates as a key indicator of problematic urban environments. Using multi-level modelling and cross-level interactions between individual age and neighbourhood disadvantage, we show that older people are in fact less responsive to environmental threats than younger adults, and provide some evidence that this is partly due to the stronger community attachment of older adults.

\section{Literature review}

\section{Fear of crime and age}

Fear of crime is best understood as a multi-faceted construct comprising cognitive, affective and behavioural dimensions (Hale, 1996; Gabriel and Greve, 2003; Collins, 2016). Studies heeding this complexity and employing multiple survey instruments have shown that higher fear levels in older age are limited to only some dimensions and appear less paradoxical than early research had suggested. Older adults are not 
generally more afraid of crime and do not perceive higher victimisation risks than younger people, but they tend to feel less safe walking in their residential areas and show more precautionary behaviour, i.e. by avoiding certain places or walking outdoors during dark hours (LaGrange and Ferraro, 1989; Greve, 1998; Kappes et al., 2013). Physical frailty is often assumed to be a major underlying process (see below). Concerning this localised perception of unsafety, many studies have found a U-shaped age-fear association, with the youngest as well as the oldest age groups, and particularly young women, being more fearful than middle-aged people (Reuband, 1989; Cobbina et al., 2008; Hummelsheim et al., 2011; Köber and Oberwittler, 2019). However, in contrast to older adults, adolescents and young adults actually face the highest risks of violent victimisation which makes their fear of crime appear less paradoxical.

What had initially been coined the 'victimisation-fear paradox' regarding the mismatch in older age groups between much lower victimisation risks but higher levels of fear is often explained using the concept of vulnerability (Greve, 1998; Jackson, 2009; Easton, 2013). According to Skogan and Maxfield (1981: 69; similarly Killias, 1990), physical vulnerability is the 'openness to attack, powerlessness to resist attack, and exposure to traumatic physical (and probably emotional) consequence if attacked'. People who feel more vulnerable due to physical frailty, psychological traits or scarce socio-economic resources may anticipate more severe consequences if victimised, and hence may have good reason to be more worried about crime. Most research agrees that older people are or perceive themselves as more vulnerable because of their vanishing physical strength (Fattah and Sacco, 1989: 212-226; Hale, 1996: 100-103). The gerontological literature suggests that physical decline starts at later mid-life and continues with a constant or possibly increasing speed (Baltes and Smith, 2003; Frederiksen et al., 2006; Hank et al., 2009a, 2009b). In support of the vulnerability approach, an analysis of the 2004 Health and Retirement Study showed that self-rated health completely mediated the effect of perceived unsafety on leisure-time physical activity (Tucker-Seeley et al., 2009).

An additional yet mostly overlooked issue is the possibility that age effects on fear of crime may conceal cohort effects (Ferraro and LaGrange, 1992; Gray et al., 2018; Köber and Oberwittler, 2019). Cohort effects are enduring influences received during the formative period of the lifecourse, typically during childhood and adolescence, on a collective group of people born in a defined historical timespan. As longitudinal or repeated cross-sectional data over a considerable time period are needed to disentangle cohort from age effects, knowledge about these complex temporal dimensions is still sparse. However, it seems useful to keep in mind that cross-sectional age effects reflect not only chronological age but also the societal circumstances when people were born and raised.

\section{Fear of crime and neighbourhood conditions}

The neighbourhood context is a crucial layer of analysis in fear of crime research. One widely used survey standard item of fear of crime asks respondents about their feelings of safety in their residential areas which we call 'localised fear' in this article. The limitations of this question, specifically that is does not explicitly refer to crime as the object of fear, are noted in the literature (Ferraro and LaGrange, 1987), 
yet scholars do agree that this question broadly captures residents' shared perceptions of neighbourhood problems and dangers. Empirically, this interpretation is supported by the substantial shares of neighbourhood-level variance (usually expressed in the intraclass correlation coefficient (ICC)) in studies using spatially clustered samples and applying multi-level analysis (Oberwittler, 2008; Wyant, 2008; Brunton-Smith and Sturgis, 2011). In the long tradition of communities and crime studies, fear of crime has played a pivotal role as a social reaction to disorder and crime undermining trust and social cohesion and potentially fuelling downwards spirals of neighbourhood decline (Taylor, 2001; Robinson et al., 2003; Brunton-Smith and Jackson, 2012; Drakulich, 2013, 2015; Häfele, 2013; Brunton-Smith et al., 2014; Skogan, 2015; Janssen et al., 2019). However, while evidence on the effects of crime and disorder on localised fear have been mixed, partly for intricate methodological reasons (Skogan, 2015), many studies have found robust associations with neighbourhood social disadvantage, typically measured by census-based poverty and ethnic minority indicators. For example, in their seminal analysis of the British Crime Survey, Brunton-Smith and Sturgis (2011) found that socio-demographic variables including poverty, urbanisation and ethnic heterogeneity explained 30 per cent of the neighbourhood variance in worries about crime, whereas the inclusion of recorded crime rates and systematic observation of disorder added only 4 per cent to the explained variance. Stronger associations of localised fear with neighbourhood social disadvantage relative to crime and disorder have also been found in several studies in the United States of America (Scarborough et al., 2010; Drakulich, 2013; Cossman et al., 2016), Sweden (Mellgren, 2011) and Germany (Lüdemann, 2006; Oberwittler, 2008; Häfele, 2013; Janssen et al., 2019). In previous analyses of the two surveys used in this paper, police-recorded neighbourhood crime rates had no effect on fear of crime after controlling for social disadvantage and other socio-demographic variables (Oberwittler et al., 2017; Sargeant et al., 2017). These findings have shifted away the attention from crime as the main cause of fear, lending support to an interpretation which stresses the broader, expressive meanings of fear of crime. In this view, crime serves as a 'metaphor for social problems in the local community and to wider society' (Jackson, 2004: 961), extending far beyond perceived victimisation risks. Residents in areas of concentrated disadvantage have more reason to express anxieties about social and economic threats, as high levels of unemployment and poverty signal a marginalised position in the social structure and exacerbate the already-reduced sense of personal control among lower-class individuals (Ross et al., 2001; Kraus et al., 2012). Sampson (2009) argued that social conditions and 'ultimately inequality' shape people's perceptions of neighbourhood reputation. Many studies have shown that feelings of unsafety in disadvantaged neighbourhoods are very closely linked to low levels of collective trust and social cohesion among residents. Both are connected aspects of the social fabric of neighbourhoods that are strongly associated with structural disadvantage (Garcia et al., 2007; Tolsma et al., 2009; Hinkle, 2013; Brunton-Smith et al., 2014; Sargeant et al., 2017; Wickes, 2017; Collins and Guidry, 2018; Laméris et al., 2018). The same is true for neighbourhood attachment and satisfaction which is also dented in disadvantaged areas, and particularly among residents who feel more unsafe in their local areas (Kullberg et al., 2010; Permentier et al., 2011; Hipp, 2013; Boschman, 2018; Sharp, 2018). 
Taken together, research has produced robust evidence that feelings of safety in congruence with broader perceptions of neighbourhood social cohesion are constrained in urban areas suffering from structural disadvantage more than from high crime loads.

\section{Person-environment interactions in fear of crime}

Much less effort has been devoted to the question of how and why individual residents react differently to problematic environmental influences. Traditionally, fear of crime research has either focused on individual or on collective, neighbourhood-level characteristics, but the interplay between individual and neighbourhood factors has only slowly received attention. As examples of recent research, Brunton-Smith and Sturgis (2011) found that gender, ethnicity and personal victimisation moderate the effects of neighbourhood-level characteristics on fear of crime; Snedker (2015) looked at gender differences in neighbourhood effects on fear; and Oberwittler et al. (2017) found that xenophobic attitudes moderate the effect of neighbourhood ethnic diversity on fear.

More to the focal issue of this paper, few studies have systematically investigated differential neighbourhood effects on safety perceptions - or wellbeing more generally - by age or by physical or mental vulnerabilities which may increase with age. The influential 'environmental docility hypothesis' developed very early by Lawton and Simon (1968; $c f$. Lawton, 1990) proposed that older adults' wellbeing is more susceptible to environmental influences than that of younger adults. Their key assumption was that 'the more competent the organism - in terms of health, intelligence, ego strength, social role performance, or cultural evolution - the less will be the proportion of variance in behaviour attributable to physical objects or conditions around him' and, reversely, a 'reduction in competence, or "deprived status", heightens his behavioural dependence on external conditions' (Lawton and Simon, 1968: 108). Considering secular changes in the ageing process in developed societies, Wahl and Gerstorf (2018; Gerstorf et al., 2015) have recently maintained that the increased susceptibility to contextual influences may be restricted to the Fourth Age when physical and cognitive decline starts more forcefully. The decline of competences is supposed to render older people more exposed and vulnerable to the adversities associated with disadvantaged neighbourhoods.

The current literature testifies to the continuing weight of the environmental docility hypothesis in gerontological research on wellbeing (Schieman, 2009; Cramm et al., 2013; Michael and Yen, 2014; Cagney and Cornwell, 2018), yet there still is a dearth of studies actually testing the hypothesis that older adults are more susceptible to environmental adversities than younger age groups. In a study of women of all ages, neighbourhood social capital had the strongest impact on self-rated health for women between 60 and 84 years (Eriksson and Ng, 2015) and similarly, Robert and $\mathrm{Li}$ (2001) found the age group 60-69 years to be most affected by neighbourhood disadvantage. However, most studies in ageing research are exclusively based on specialised samples of older adults. In a systematic review on health effects of neighbourhood environments on older people, Yen et al. (2009) found only one study covering the complete adult lifespan, and a systematic review by Annear et al. (2014) a priori restricted the search process to studies of older 
adults starting at 50 years. While it is logical that gerontological research focuses on older people, the unavoidable consequence of an exclusive focus is that comparisons across different age groups are rendered impossible.

The opposing viewpoint that older people may be less susceptible to environmental conditions has received much less support, although it can be traced back to the early years of research on fear of crime. Maxfield (1984: 246) found that older residents were not more fearful than younger residents in more problematic neighbourhoods: 'When crime is a particular feature of the neighbourhood environment, the high fear levels of older residents are shared by their more youthful neighbors. In such neighborhoods everyone is more afraid.' The same result was reported by McGarrell et al. (1997) with respect to the impact of neighbourhood disorder on fear of crime: only in the neighbourhoods with low disorder did fear significantly increase with age. Both studies were restricted to a handful of neighbourhoods which severely limits the generalisability of results, and no consistent $\mathrm{P} \times \mathrm{E}$ hypothesis emerged from them.

In ageing research, Wahl and colleagues (Oswald et al., 2006; Wahl et al., 2007, 2012) provided a possible explanation why older adults may be less affected by adverse neighbourhood conditions: older residents often live in the same neighbourhood for decades and may develop a very strong place attachment or 'sense of place identity' (Wahl and Gerstorf, 2018: 163). Social interactions with neighbours, daily routines and autobiographical memories accumulate over many years to build strong familiarities and emotional bonds to the place of residence (Wahl et al., 2007: 105). Consequently, older people may 'value their familiar home and neighbourhood environment, even if they present inherent risks' (Wahl et al., 2012: 309). According to this perspective, place attachment furnishes older residents to endure or ignore problematic neighbourhood conditions, thus making them more resilient.

Some studies have confirmed the fear-reducing effect of place attachment. De Donder et al. (2012), in a large survey of older adults in Belgium, found that unsafety perceptions were lower for respondents with higher place attachment and civic engagement, and a study of older adults in Florida found that neighbourhood dissatisfaction was the strongest predictor of fear of crime (McCoy et al., 1996). Concerning a related aspect of place attachment, McNeeley and Stutzenberger (2013; cf. Hipp, 2011) reported that the inclination to move to a different neighbourhood was decreasing with age, controlling for risk perception and actual victimisation experiences.

As stated above, very few studies have explicitly tested hypotheses based on $\mathrm{P} \times \mathrm{E}$ theories of age and fear of crime. As a precondition, an appropriate study design must include both a respondent sample across the complete adult lifespan as well as a sufficient number and diversity of neighbourhood contexts. Due to the dearth of such studies, the question of whether older adults are more, less or equally vulnerable to adverse neighbourhood conditions than younger age groups with regard to fear of crime has remained largely unanswered. We contribute to closing this research gap by investigating cross-level interactions between age and neighbourhood social disadvantage on localised fear of crime in two large-scale community studies from Australia and Germany. 


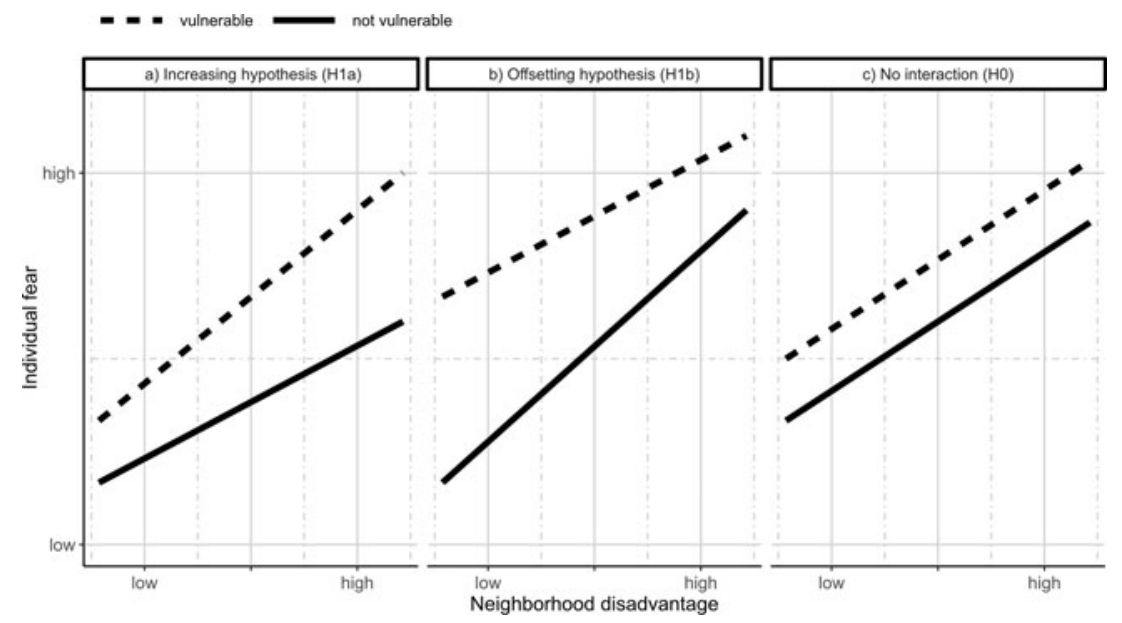

Figure 1. Interactions between individual vulnerability and neighbourhood disadvantage.

\section{Current study}

\section{Hypotheses and study context}

The central research question of this article is whether the impact of neighbourhood social disadvantage on localised fear of crime is stronger, weaker or the same for older adults compared to younger age groups. Figure 1 graphically illustrates these three hypothetical outcomes of this cross-level interaction between individual age and neighbourhood conditions. Hypothesis 1a (H1a) follows the 'environmental docility hypothesis' (Lawton and Simon, 1968) and assumes that the effect of neighbourhood disadvantage on fear of crime is stronger in higher age, while Hypothesis $1 \mathrm{~b}(\mathrm{H} 1 \mathrm{~b})$ takes the opposite stance that the effect of neighbourhood disadvantage on fear of crime is weaker in higher age, in line with Maxfield (1984) and McGarrell et al. (1997). If H1a and H1b were not accepted, $\mathrm{HO}$ - the effects of neighbourhood disadvantage on localised fear are not dependent on age - would be maintained. Given the sparse and inconclusive research on this issue, we do not take sides for either alternative hypothesis.

The additional Hypothesis $\mathrm{H} 2(\mathrm{H} 2)$ builds on $\mathrm{H} 1 \mathrm{~b}$ and posits that in case older adults are in fact less vulnerable to adverse neighbourhood conditions than younger ages, this can be explained by a stronger place attachment of older people which works as a psychological buffer against environmental adversities, following the reasoning of Wahl and colleagues (Oswald et al., 2006; Wahl and Gerstorf, 2018). Thus, $\mathrm{H} 2$ assumes that neighbourhood attachment acts as a mediator of the $\mathrm{P} \times \mathrm{E}$ effect of age and neighbourhood disadvantage.

We investigate these research questions using two community surveys from Germany and Australia and employing multi-level analysis. The two surveys used a set of near-identical items designed to advance the knowledge about the conditions and consequences of neighbourhood social processes including safety perceptions in large cities, alongside questions on the socio-demographic 
background. Both surveys had a very similar design, based on probability samples of the adult population in large samples of urban neighbourhoods located in two cities in Australia (Melbourne and Brisbane) and two cities in Germany (Cologne and Essen).

By comparing Australian and German cities, we aim to enhance the crossnational generalisability of findings. If the comparison of two independent studies from different countries yields the same results, this would render the conclusions more robust. Both countries belong to the group of highly developed nations. Australia ranked second and Germany sixth in the 2014 Human Development Index (United Nations Development Programme, 2015). Germany's per capita Gross Domestic Product (GDP) was US \$47,200, Australia's per capita GDP was US $\$ 47,600$ in 2014 (Organisation for Economic Co-operation and Development (OECD), 2019). The unemployment rate was 5.0 per cent in Germany and 6.1 per cent in Australia. There are also some structural differences between the two countries: Australia is more urbanised, with 70.1 per cent of the population residing in urban regions compared to 57.1 per cent in Germany. In contrast to Australia, the regional distribution of urban wealth was more unequal in Germany, with some large cities scoring considerably below the national average in mean household income (OECD, 2018: 103), and with signs of larger social segregation within cities. Both German cities had unemployment rates above the national average (9.6\% in Cologne, $12.4 \%$ in Essen), whereas the Australian cities roughly matched the national average (5.9\% in Melbourne, 5.5\% in Brisbane).

Due to a very low fertility rate, Germany has a rapidly ageing population, and the share of the population aged 65 years and over was considerably higher in Germany (21.5\%) than in Australia (14.7\%). As a rough indicator of serious crime, both countries had very low homicide rates of around one per 100,000 inhabitants.

\section{Data}

\section{Sample characteristics}

To investigate Australian neighbourhoods, we used data from the Australian Community Capacity Study which was conducted in 2010 as a computer-assisted telephone interview survey in 295 neighbourhoods in Brisbane (Wave 3) and Melbourne (Wave 1), with an overall response rate of 32.6 per cent. For Germany, we used the first wave of the SENSIKO study conducted in 2014, a postal survey with a response rate of 41 per cent in 140 neighbourhoods in Cologne and Essen (Table 1). Both surveys used sampling frames of the general adult population residing in private dwellings - from age 18 in Australia and 25-90 years in Germany-without special regard to possible age-related physical or cognitive impairments. Residents in care homes, and hence a section of the particularly impaired older population, were excluded from both surveys. Older adults are generally known as an easier-to-reach demographic group in surveys (Mulry, 2014). Physical impairments - except grave hearing impairments in telephone surveys and visual impairments in mail surveys - do not necessarily hamper survey participation. Age-specific response rates in the German survey were in fact highest for the age bracket 70-79 years, and still higher for the age bracket 80-89 compared to all age groups under 50 years. ${ }^{1}$ Participation in both surveys was dependent on 
Table 1. Descriptive statistics of countries and cities

\begin{tabular}{ccc}
\hline Sample areas & N & $\%$ \\
\hline Germany: & 3,910 & 100.0 \\
\hline Cologne & 2,335 & 59.7 \\
\hline Essen & 1,575 & 40.3 \\
\hline Australia: & 8,710 & 100.0 \\
\hline Brisbane & 4,115 & 47.2 \\
\hline Melbourne & 4,595 & 52.8 \\
\hline
\end{tabular}

sufficient cognitive capabilities. Systematic information on cognitive impairments in the target population was unavailable. However, approximately 8 per cent of the non-response among the age group 70 years and older in the German sample could be attributed to dementia and frailty based on information given by other household members (Gerstner and Oberwittler, 2016). Restricting the samples to the age range 25-90 years - the predefined sampling frame in Germany - the sample sizes were 3,910 respondents in Germany and 8,710 respondents in Australia. Reflecting a near-identical sampling design aimed at roughly even numbers of respondents in all neighbourhoods, the mean numbers of respondents per neighbourhood were similar in Australia (21.4) and Germany (28.0). No weights were applied because all relevant characteristics were included in the models.

Australian neighbourhoods in this study were based on suburbs within broader statistical local areas; German neighbourhoods were based on smaller administrative units. The Australian neighbourhoods were considerably larger both in terms of population (mean $=6,645)$ and area size (mean $=14.6$ square kilometres $\left(\mathrm{km}^{2}\right)$ ) than the German neighbourhoods (population mean $=2,880$; area size mean $=0.56 \mathrm{~km}^{2}$ ). These differences in part reflect different geographic layouts of urban areas in the two countries, with larger geographic pattern and much lower population densities in Australia compared to Germany. The impact of varying spatial definitions on results is a recurring topic in geographic research. While smaller spatial units are generally believed to yield stronger effects due to higher homogeneity, effects often have been found to be robust on different scales (Oberwittler and Wikström, 2009; Hipp, 2010; Lawton, 2018).

\section{Dependent variable}

Our dependent variable is a version of the standard item of fear of crime which measures feelings of unsafety in the respondents' residential neighbourhoods. The question in Australia was worded: 'I feel safe walking down the street after dark', using five answer categories from 'strongly agree' to 'strongly disagree'; and in Germany: 'How safe do you feel - or would you feel - walking alone after dark in your area of residence?', using only four answer categories from 'very safe' to 'very unsafe'. 'Area of residence' was defined in the German questionnaire as the area around one's home accessible within ten minutes' walking.

The issue of even or uneven numbers of answer categories is a long-standing theme in survey research (Sturgis et al., 2014). Based on other analyses of the 
Table 2. Descriptive statistics of fear of crime

\begin{tabular}{lccccc}
\hline & \multicolumn{2}{c}{ Germany } & & \multicolumn{2}{c}{ Australia } \\
\cline { 2 - 3 } Value & $\mathrm{N}$ & $\%$ & $\mathrm{~N}$ & $\%$ \\
\hline 0 & 546 & 13.9 & 1,994 & 22.9 \\
\hline 0.25 & - & - & 4,225 & 48.5 \\
\hline 0.33 & 2,026 & 51.8 & - & - \\
\hline 0.5 & - & - & 573 & 6.6 \\
\hline 0.67 & 1,046 & 26.8 & - & - \\
\hline 0.75 & - & - & 1,555 & 17.9 \\
\hline 1 & 279 & 7.1 & 330 & 3.8 \\
\hline Missing & 13 & 0.3 & 33 & 0.4 \\
\hline
\end{tabular}

same datasets, we assume only small effects of the diverging number of answer categories (cf. Gerstner et al., 2019). For the comparative analyses, the item was standardised to a minimum value of 0 and a maximum of 1 in each country - similar to a percentage of maximum possible score (e.g. Cohen et al., 1999). Table 2 shows the distribution of the dependent variable in both countries. To rule out a potential bias, we ran alternative models using a random allocation of the middle category to either safe or unsafe in the Australian sample, and the results were nearly identical to those reported below and are available on request.

With its explicit reference to the respondents' neighbourhoods, this question is well-suited and has often been employed to measure localised fear of crime (Greve, 1998; Gibson et al., 2002; Oberwittler, 2008; Alper and Chappell, 2012; Häfele, 2013; Sargeant et al., 2017). However, the standard item has also been subjected to criticism. Concerns have centred on the absence of an explicit reference to crime and the implicit focus on violent street crime. Further, while the affective dimension clearly prevails, it may be assumed that the question evokes all three dimensions of fear of crime (affective, cognitive and behavioural) to varying degrees (Ferraro and LaGrange, 1987; Farrall et al., 1997; Kreuter, 2002; Häfele, 2013). Many scholars favour an interpretation of the standard item which stresses the broader and expressive meanings of fear of crime (see the section 'Fear of crime and neighbourhood conditions' above). Lastly, its lack of specificity may invite different cognitive associations from different demographic groups: women may associate the question with the threat of a sexual assault while older people may fear accidents (e.g. stumbling or falling) more than criminal assaults. While such criticism is not unfounded, studies have demonstrated that a clear majority of people connect this question with crime (Reuband, 2000), also indicated by strong correlations with other measures of fear of crime. In the German sample, the standard item of localised fear correlated strongly with avoidance behaviour (Spearman's rank correlation coefficient $\rho=0.62)$ and crime-specific affective fear $(\rho=0.46)$, and moderately with cognitive fear of crime $(\rho=0.32)$. Supportive of this interpretation, an in-depth analysis of the German sample using crime-specific affective fear 
as an alternative outcome found very similar results to those reported by Köber (2018).

\section{Independent variables}

Age was restricted to 25-90 years, the predefined age range of the German survey sample. The mean age was 52.9 with a standard deviation (SD) of 14.2 and seven missing values in the Australian sample, and a mean of $53.0(\mathrm{SD}=14.2,104$ missing values) in the German sample. In the regression models, we used orthogonal polynomials of age to circumvent multicollinearity between the linear and quadratic age variables which also eases the interpretation of the interaction terms of age with gender and neighbourhood disadvantage (Narula, 1979).

Education was measured using the International Standard Classification of Education (UNESCO Institute for Statistics, 2006) recoded to five categories (Table 3). The economic status was assessed differently in both surveys. The Australian survey asked respondents for the approximate annual household income. The high number of missing values in Australia was included as a residual indicator category. In the German survey, three questions addressed subjective income and wealth, resulting in considerably fewer missing values. Respondents were asked whether they received social benefits during the last 12 months; second, whether they were capable of paying a large bill; and third, whether their household income was sufficient to make ends meet. A factor analysis based on polychoric correlations suggested an acceptable fit for a one-dimensional solution. We grouped the resulting variables in both countries to quartiles of an ordinal measurement of the economic status, with higher values representing more affluence. Education correlated more strongly with economic status in Germany than in Australia $(\rho=0.29$ versus $\rho=0.12$ ).

Migration status distinguished respondents who were born in Australia from Germany from those born abroad. We asked respondents about the length of residence, using categories from up to one year to more than 20 years. We recoded this variable to up to two years, 2-20 years, and more than 20 years based on group and effect size considerations. Neighbourhood attachment was based on single survey questions: 'Do you feel truly "at home" in your neighbourhood?' (with four answering categories: 'truly at home' to 'not at home at all') in the German sample and 'I feel that I belong to this local community' (with five answering categories: 'strongly agree' to 'strongly disagree') in the Australian sample.

We used the unemployment rate as a proxy for neighbourhood social disadvantage because it was available in both countries and based on a common definition. In the absence of direct measurements of income or poverty in Germany, the unemployment rate is a strong indicator for neighbourhood deprivation. The unemployment rate was significantly higher in German (mean $=10.4, \mathrm{SD}=5.9$ ) than in Australian neighbourhoods (mean $=3.4, \mathrm{SD}=1.2$ ), reflecting considerably higher levels of unemployment in the German cities. Whereas unemployment rates in Australian neighbourhoods varied between a minimum of zero and a maximum of 6 per cent (in Melbourne) and 8 per cent (in Brisbane), the range of values was much larger in Germany, with the lowest values around 2 per cent and the highest values around 26-28 per cent in Cologne and Essen. These cross-national differences in neighbourhood unemployment rates indicate not only higher levels 
Table 3. Descriptive statistics of independent and control variables

\begin{tabular}{|c|c|c|c|c|}
\hline \multirow[b]{2}{*}{ Level } & \multicolumn{2}{|c|}{ Germany } & \multicolumn{2}{|c|}{ Australia } \\
\hline & $\mathrm{N}$ & $\%$ & $\mathrm{~N}$ & $\%$ \\
\hline \multicolumn{5}{|l|}{ Gender: } \\
\hline Male & 1,710 & 43.7 & 3,395 & 39.0 \\
\hline Female & 2,200 & 56.3 & 5,315 & 61.0 \\
\hline \multicolumn{5}{|l|}{ Economic status: } \\
\hline 1st quartile & 1,450 & 37.1 & 2,624 & 30.1 \\
\hline 2nd quartile & 868 & 22.2 & 957 & 11.0 \\
\hline 3rd quartile & 1,050 & 26.9 & 1,613 & 18.5 \\
\hline 4th quartile & 522 & 13.4 & 1,422 & 16.3 \\
\hline Missing & 20 & 0.5 & 2,094 & 24.0 \\
\hline \multicolumn{5}{|l|}{ Education (ISCED): } \\
\hline No degree $/ 1 \mathrm{~A}$ & 108 & 2.8 & 279 & 3.2 \\
\hline $2 \mathrm{~A}$ & 993 & 25.4 & 1,481 & 17.0 \\
\hline $3 \mathrm{~B}$ & 787 & 20.1 & 1,624 & 18.6 \\
\hline $3 \mathrm{~A}$ & 641 & 16.4 & 1,868 & 21.4 \\
\hline $5 A, 6$ & 1,100 & 28.1 & 3,401 & 39.0 \\
\hline Other/missing & 281 & 7.2 & 57 & 0.7 \\
\hline \multicolumn{5}{|l|}{ Migration status: } \\
\hline Born in Australia or Germany & 3,145 & 80.4 & 6,176 & 70.9 \\
\hline Foreign-born & 699 & 17.9 & 2,482 & 28.5 \\
\hline Missing & 66 & 1.7 & 52 & 0.6 \\
\hline \multicolumn{5}{|l|}{ Length of residence: } \\
\hline Up to 2 years & 266 & 6.8 & 256 & 2.9 \\
\hline $2-10$ years & 1,727 & 44.2 & 3,860 & 44.3 \\
\hline 10 or more & 1,902 & 48.6 & 4,512 & 51.8 \\
\hline Missing & 15 & 0.4 & 82 & 0.9 \\
\hline
\end{tabular}

Note: ISCED: International Standard Classification of Education.

of social disadvantage in German compared to Australian cities but also higher levels of social segregation, with urban areas of concentrated disadvantage in which sizeable shares of residents are affected by poverty (Mustered et al., 2006; Kronauer and Siebel, 2013). Violent crime rates were constructed as the number of police-recorded violent offences against the person (homicide, assault, robbery) divided by 100,000 resident population and were log-transformed to normalise their highly skewed distribution. The violent crime rates on the log scale were slightly higher in Germany (mean $=6.9, \mathrm{SD}=0.9$ ) than in Australia (mean $=6.2$, 


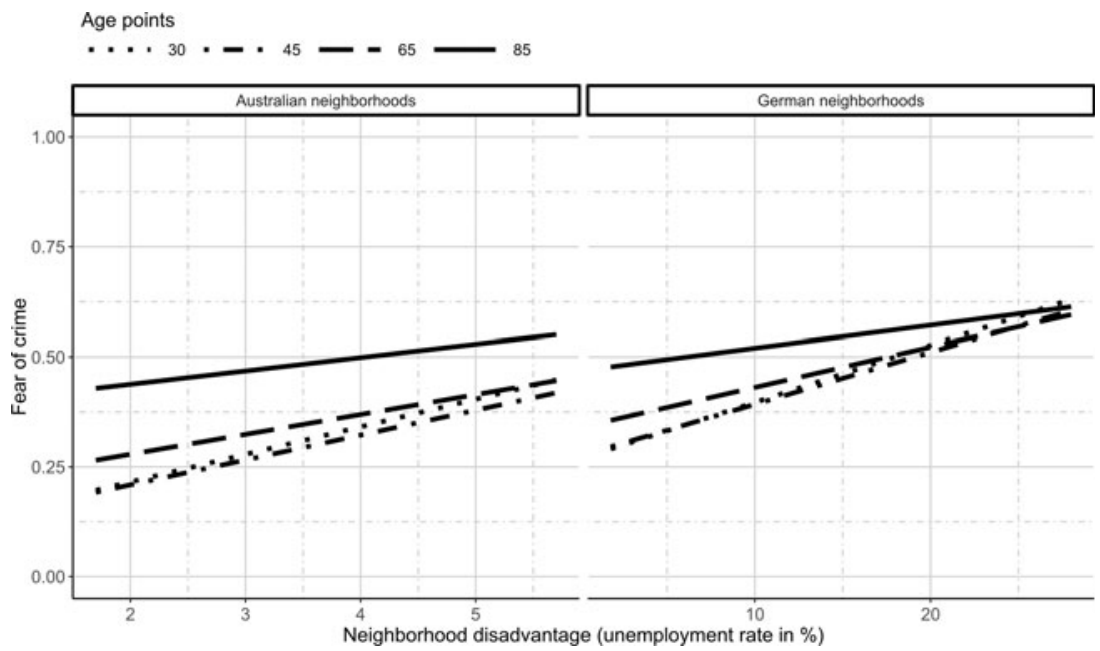

Figure 2. Predicted effect of neighbourhood social disadvantage on fear of crime depending on age (by country).

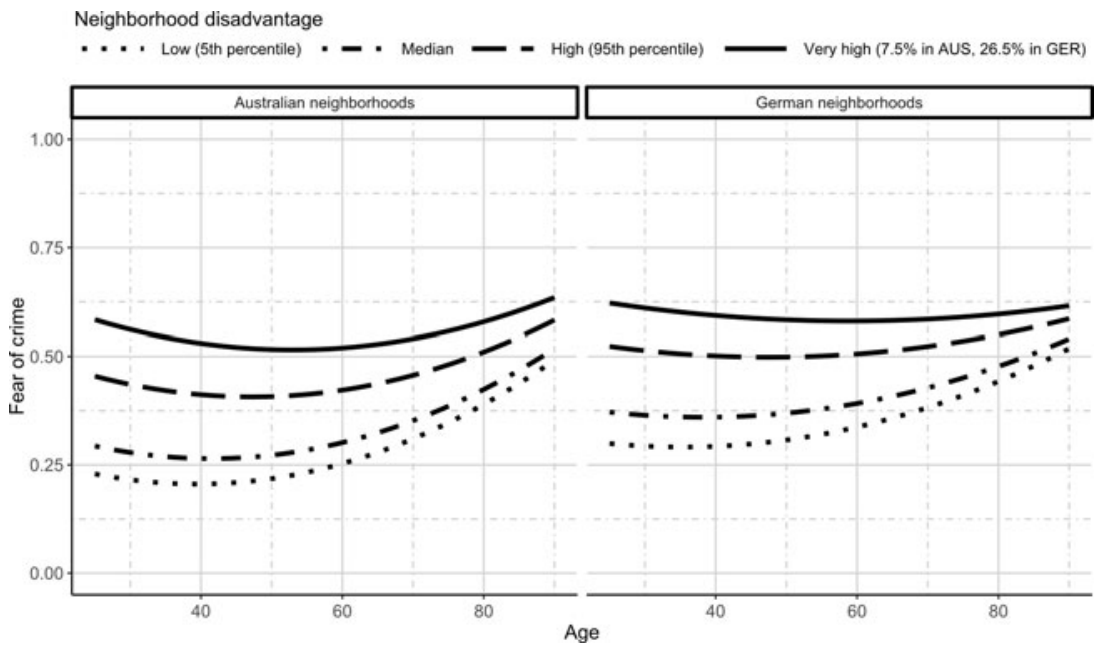

Figure 3. Predicted effect of age on fear of crime depending on neighbourhood social disadvantage (by country).

Notes: AUS: Australia. GER: Germany.

$\mathrm{SD}=1.4)$. We standardised both neighbourhood variables within countries to make the regression coefficients more comparable but left the unemployment rate untransformed in Figures 2 and 3 to provide a more natural interpretation of the graphs. As we are not interested in explaining level differences in fear between the two countries, within-country standardisation is suitable for the cross-national 
analysis of the effect sizes (slopes) of this predictor and how they vary by age, but would not be suitable for investigating level differences in fear of crime between the two countries (which we do not intend in this paper).

\section{Analytic strategy}

Considering the hierarchical structure of our survey data with respondents nested in neighbourhoods, we ran multi-level regression models to analyse individualand neighbourhood-level predictors of fear of crime simultaneously, as well as cross-level interactions between age and neighbourhood disadvantage. After null and conditional models for assessing the ICC of fear of crime by age groups, we fitted three equivalent linear multi-level regression models by country to test our two main hypotheses. We preferred linear over ordered logistic modelling because of the well-known difficulties of model comparisons (Mood, 2010) and interaction effects due to the non-linear relationship between logits and probabilities ( $\mathrm{Ai}$ and Norton, 2003; Greene, 2010).

The first baseline model (Model 1) was a random intercept model with all individual-level predictors (except neighbourhood attachment) and neighbourhood disadvantage, Model 2 tested the cross-level interaction between age and neighbourhood disadvantage controlling for violent crime rates and Model 3 added neighbourhood attachment as a mediating predictor.

In modelling the cross-level interaction between age and neighbourhood disadvantage, we followed Snijders and Bosker's (2012: 82, 105) advice to include the multiplicative term on theoretical grounds, irrespective of the existence of a random slope for age. ${ }^{2}$ The importance of the cross-level interaction was assessed in two ways: first, the significance of the interaction terms was tested based on Satterthwaite's approximation of degrees of freedom; second, an improvement of the global fit was assessed with the Akaike information criterion (AIC) which penalises additional coefficients less strongly than the equationally similar Bayesian information criterion. For both, smaller values indicate a better overall quality of the model.

As interaction effects are notoriously difficult to interpret from regression coefficients, we reported marginal means and showed marginal effects plots to gain insights into their substantive meaning (Brambor et al., 2006). It is important to consider that interaction effects are symmetric and operate 'both ways': the effects of both interaction variables depend on the respective other (Berry et al., 2012). Therefore, both the variable effect of neighbourhood disadvantage depending on age as well as the variable effect of age depending on neighbourhood disadvantage should be considered to gain a full picture of the mutual dependency. Due to the quadratic relationship between age and fear, the marginal effect of age (which is the derivative of the regression equation to age) is depending on neighbourhood disadvantage and age. In other words, the effect of age is constant neither across the range of age nor neighbourhood disadvantage (Aiken et al., 1991: chap. 5). Therefore, we plotted the marginal age effects depending on neighbourhood disadvantage at four age points $(25,45,65$ and 85 years).

Computationally, we used R (R Core Team, 2016) and the packages lme4 for the regression analysis (Bates et al., 2015), effects (Fox, 2003) for the prediction, mgcv 
Table 4. Conditional intraclass correlation coefficients (ICCS) of localised fear of crime by age groups

\begin{tabular}{lcccc}
\hline & \multicolumn{3}{c}{ Age group } \\
\cline { 2 - 5 } & All & $<40$ & $40-59$ & $>59$ \\
\hline Australia & 12.1 & \multicolumn{3}{c}{ Percentages } \\
Germany & 13.6 & 15.8 & 13.7 & 7.6 \\
\hline
\end{tabular}

Note: Conditional ICCs controlling for education, economic status, migration, length of residence and gender.

(Wood, 2017) for the generalised additive models and ggplot2 (Wickham, 2016) as well as lattice (Sarkar, 2008) for visualisations.

\section{Results}

As an exploratory step of analysis, we first look at the ICCs of localised fear of crime in different age groups controlling for individual socio-demographic composition. This ICC measures the share of between-neighbourhood variance which signifies the potential influence of any neighbourhood conditions on localised fear. Table 4 shows that the overall ICC was roughly of the same size in Germany and Australia: in the overall sample, 13.6 per cent of the variance in Germany and 12.1 per cent in Australia was between the neighbourhoods, indicating potentially large influences of neighbourhood characteristics on localised fear of crime. Differentiated by age groups, both countries showed a tendency of decreasing ICCs by age groups, yet this tendency was stronger in Australia. Here, the ICC for older respondents (60 years and older) was only half of that for respondents under 40 years; in Germany, the difference was 3.1 percentage points. Smaller ICCs indicate a decreased potential impact of neighbourhood conditions on safety perceptions.

Turning to the multi-level regression models (Table 5), Model 1 shows the results for the baseline random incept model without the $\mathrm{P} \times \mathrm{E}$ interaction effect. Most of the individual-level effects of socio-demographic variables were very similar in both countries and in line with previous research. Female respondents reported more fear than male respondents, and age was curvilinearly related to fear: with higher age, respondents became increasingly more fearful. Only in Australia was the curvilinear age effect on fear stronger for women, indicated by a significant interaction between gender and age squared.

Social status variables impacted fear in very similar ways in Germany and Australia: lower-educated and poorer people were more fearful compared to highereducated and more affluent people, again in line with previous research. The effect of education, and in particular of high educational degrees, was stronger in Germany than in Australia. The positive effect of the residual 'missing' category of economic status in Australia suggests that many of the 24 per cent of respondents who did not want to report their income may belong to lower-income groups. Migration background did not affect fear of crime in either country. Length of residence had, if at all, a rather small influence on fear in Germany. In Australia, both people who moved into a neighbourhood recently and who lived there for more 
Table 5. Linear multi-level regression models of fear of crime

\begin{tabular}{|c|c|c|c|c|c|c|}
\hline & \multicolumn{3}{|c|}{ Germany } & \multicolumn{3}{|c|}{ Australia } \\
\hline & Model 1 & Model 2 & Model 3 & Model 1 & Model 2 & Model 3 \\
\hline Age $^{1,2}$ & $0.07(0.01)^{\star \star \star}$ & $0.07(0.01)^{\star \star \star}$ & $0.08(0.01)^{\star \star \star}$ & $0.05(0.01)^{\star \star \star}$ & $0.05(0.01)^{\star \star \star}$ & $0.06(0.01)^{\star \star \star}$ \\
\hline Age squared & $0.03(0.01)^{\star \star}$ & $0.03(0.01)^{\star \star}$ & $0.04(0.01)^{\star \star}$ & $0.04(0.01)^{\star \star \star}$ & $0.03(0.01)^{\star \star \star \star}$ & $0.03(0.01)^{\star \star}$ \\
\hline Gender: women & $0.09(0.01)^{\star \star \star}$ & $0.09(0.01)^{\star \star \star}$ & $0.09(0.01)^{\star \star \star}$ & $0.11(0.01)^{\star \star \star}$ & $0.12(0.01)^{\star \star \star}$ & $0.12(0.01)^{\star \star \star}$ \\
\hline Women $\times$ Age $^{1,2}$ & $-0.02(0.02)$ & $-0.03(0.02)$ & $-0.03(0.01)^{\star}$ & $0.02(0.01)^{\star}$ & $0.02(0.01)^{\star}$ & $0.02(0.01)$ \\
\hline Women $\times$ Age squared & $0.003(0.02)$ & $0.0003(0.02)$ & $0.001(0.01)$ & $0.02(0.01)^{\star}$ & $0.03(0.01)^{\star}$ & $0.03(0.01)^{\star \star}$ \\
\hline Neighbourhood disadvantage $\mathrm{A}^{2,3} \times \mathrm{Age}^{1,2}$ & & $-0.05(0.01)^{\star \star \star}$ & $-0.04(0.01)^{\star \star}$ & & $-0.04(0.01)^{\star \star \star}$ & $-0.03(0.01)^{\star \star}$ \\
\hline Neighbourhood disadvantage ${ }^{2,3} \times$ Age squared & & $-0.01(0.01)$ & $-0.01(0.01)$ & & $-0.005(0.01)$ & $-0.01(0.01)$ \\
\hline \multicolumn{7}{|l|}{ Neighbourhood attachment ${ }^{4}$ : } \\
\hline Very low & & & $0.24(0.02)^{\star \star \star}$ & & & $0.20(0.02)^{\star \star \star}$ \\
\hline$\cdots$ & & & $0.10(0.01)^{\star \star \star}$ & & & $0.08(0.01)^{\star \star \star}$ \\
\hline$\ldots$ & & & $-0.08(0.01)^{\star \star \star}$ & & & $-0.06(0.01)^{\star \star \star}$ \\
\hline Very high & & & & & & $-0.19(0.01)^{\star \star \star}$ \\
\hline \multicolumn{7}{|l|}{ Length of residence (Ref. 2-20 years): } \\
\hline Up to 2 years & $0.002(0.02)$ & $0.002(0.02)$ & $-0.004(0.02)$ & $-0.04(0.02)^{\star}$ & $-0.04(0.02)^{\star *}$ & $-0.04(0.02)^{\star \star}$ \\
\hline More than 20 years & $0.01(0.01)$ & $0.01(0.01)$ & $0.02(0.01)^{\star}$ & $-0.02(0.01)^{\star \star}$ & $-0.02(0.01)^{\star *}$ & $-0.01(0.01)$ \\
\hline \multicolumn{7}{|l|}{ Education (Ref. 4A): } \\
\hline No degree/1A & $0.01(0.02)$ & $0.01(0.02)$ & $0.001(0.02)$ & $0.04(0.02)^{\star \star}$ & $0.05(0.02)^{\star \star}$ & $0.06(0.02)^{\star \star *}$ \\
\hline $2 \mathrm{~A}$ & $0.02(0.01)^{\star}$ & $0.03(0.01)^{\star}$ & $0.03(0.01)^{\star}$ & $0.03(0.01)^{\star \star}$ & $0.03(0.01)^{\star \star}$ & $0.03(0.01)^{\star \star}$ \\
\hline $3 \mathrm{~A}$ & $-0.03(0.01)^{\star}$ & $-0.02(0.01)^{\star}$ & $-0.03(0.01)^{\star}$ & $0.02(0.01)^{\star}$ & $0.02(0.01)^{\star}$ & $0.01(0.01)$ \\
\hline
\end{tabular}


Table 5. (Continued.)

\begin{tabular}{|c|c|c|c|c|c|c|}
\hline & \multicolumn{3}{|c|}{ Germany } & \multicolumn{3}{|c|}{ Australia } \\
\hline & Model 1 & Model 2 & Model 3 & Model 1 & Model 2 & Model 3 \\
\hline $5 A, 6$ & $-0.07(0.01)^{\star \star \star}$ & $-0.06(0.01)^{\star \star \star}$ & $-0.07(0.01)^{\star \star \star}$ & $-0.02(0.01)^{\star}$ & $-0.02(0.01)^{\star}$ & $-0.02(0.01)^{\star \star}$ \\
\hline Missing & $-0.05(0.02)^{\star \star}$ & $-0.04(0.02)^{\star}$ & $-0.05(0.02)^{\star \star}$ & $0.12(0.05)^{\star}$ & $0.12(0.05)^{*}$ & $0.09(0.04)^{*}$ \\
\hline \multicolumn{7}{|l|}{ Economic situation (Ref. 3rd quartile): } \\
\hline 1st quartile & $0.05(0.01)^{\star \star \star}$ & $0.05(0.01)^{\star \star \star}$ & $0.03(0.01)^{\star * *}$ & $0.03(0.01)^{\star \star \star}$ & $0.03(0.01)^{\star \star \star}$ & $0.03(0.01)^{\star \star \star}$ \\
\hline 2nd quartile & $0.03(0.01)^{\star}$ & $0.03(0.01)^{\star}$ & $0.02(0.01)^{\star}$ & $-0.01(0.01)$ & $-0.01(0.01)$ & $-0.01(0.01)$ \\
\hline 4th quartile & $-0.02(0.01)$ & $-0.02(0.01)$ & $-0.02(0.01)$ & $-0.01(0.01)$ & $-0.01(0.01)$ & $-0.01(0.01)$ \\
\hline Other/missing & $0.02(0.07)$ & $0.02(0.07)$ & $-0.001(0.07)$ & $0.03(0.01)^{\star \star \star}$ & $0.03(0.01)^{\star \star \star}$ & $0.03(0.01)^{\star \star \star}$ \\
\hline Migration status: born abroad & $-0.01(0.01)$ & $-0.01(0.01)$ & $-0.01(0.01)$ & $-0.01(0.01)$ & $-0.01(0.01)$ & $-0.01(0.01)$ \\
\hline Neighbourhood disadvantage $e^{2,3}$ & $0.12(0.01)^{\star \star \star}$ & $0.12(0.01)^{\star \star \star}$ & $0.09(0.01)^{\star \star \star}$ & $0.12(0.01)^{\star \star \star}$ & $0.12(0.01)^{\star \star \star}$ & $0.10(0.01)^{\star \star \star}$ \\
\hline Neighbourhood violent crime rate ${ }^{2,3}$ & $0.05(0.01)^{\star \star \star}$ & $0.05(0.01)^{\star \star \star}$ & $0.04(0.01)^{\star \star \star}$ & $0.05(0.01)^{\star \star \star}$ & $0.05(0.01)^{\star \star \star}$ & $0.04(0.01)^{\star \star \star}$ \\
\hline City $^{3}$ : Essen (Germany); Melbourne (Australia) & $0.03(0.01)^{\star}$ & $0.03(0.01)^{\star}$ & $0.03(0.01)^{\star \star}$ & $0.06(0.01)^{\star \star \star}$ & $0.06(0.01)^{\star \star \star}$ & $0.05(0.01)^{\star \star \star}$ \\
\hline Constant & $0.36(0.01)^{\star \star \star}$ & $0.36(0.01)^{\star \star \star}$ & $0.38(0.01)^{\star \star \star}$ & $0.22(0.01)^{\star \star \star}$ & $0.21(0.01)^{\star \star \star}$ & $0.27(0.01)^{\star \star *}$ \\
\hline Akaike information criterion & -138 & -143 & -391 & 947 & 942 & 171 \\
\hline$R_{\text {individual }}^{2}(\%)$ & 9.5 & 9.8 & 15.7 & 9.5 & 9.5 & 17.3 \\
\hline$R_{\text {neighbourhood, null model }}^{2}(\%)$ & 79.1 & 79 & 84.3 & 67.2 & 68.2 & 77 \\
\hline$R_{\text {neighbourhood, conditional model }}^{2}(\%)$ & 73.5 & 73.3 & 80.1 & 63.2 & 64.2 & 74.2 \\
\hline Random intercept (SD) & 0.06 & 0.06 & 0.05 & 0.05 & 0.05 & 0.04 \\
\hline Residuals (SD) & 0.25 & 0.25 & 0.24 & 0.23 & 0.23 & 0.22 \\
\hline
\end{tabular}

Notes: 1. Orthogonal polynomials. 2. Standardised by two standard deviations to allow comparisons to categorical variables (Gelman, 2007). 3. Neighbourhood variable. 4. 'Do you feel truly "at home" in your neighbourhood?' (with four answering categories: 'truly at home' to 'not at home at all') in Germany and 'I feel that I belong to this local community' (with five answering categories: 'strongly agree' to 'strongly disagree') in Australia. Ref. Rather at home (Germany); Agree (Australia).

Abbreviations: Ref., reference category; SD, standard deviation.

Significance levels: * $p<0.05,{ }^{\star *} p<0.01,{ }^{* \star *} p<0.001$. 
than 20 years reported slightly less fear. Together, all individual-level sociodemographic variables explained just under 10 per cent of the respondent-level variance in both countries.

In the neighbourhood part of the multi-level model (Model 1), social disadvantage as measured by the standardised unemployment rate increased localised fear in both countries. The coefficients of 0.12 in both countries indicate the increase of fear on a scale between 0 and 1 for two standard deviations increase in neighbourhood disadvantage. This scaling of continuous variables makes the size of the coefficient also comparable to all categorical predictors (Gelman, 2007). Violent crime rates, too, increased fear of crime in both countries, yet the coefficient of 0.05 represents a weaker effect compared to social disadvantage, supporting previous research. Social disadvantage not only was of greater importance for the variation in local insecurities between neighbourhoods but was also stronger than most individual effects and as strong as gender which has shown very strong and robust associations with fear of crime in most studies. The pivotal relevance of neighbourhood disadvantage for localised fear is underlined by the fact that as a single predictor, it explained 69 per cent of the between-neighbourhood variance in Germany and 58 per cent of the between-neighbourhood variance in Australia, after controlling for the individual socio-demographic composition of respondents but not controlling for violent crime rates (not shown, available on request). Violent crime rates added only little (4.5\% in Germany, 5.2\% in Australia) to the explanation of local variations in insecurities. These results once again proved the strong position of social disadvantage in accounting for neighbourhood differences in residents' perceptions of safety and related social processes (Ham et al., 2012; Sampson, 2018). We included dummy variables to control for city-level differences in fear; the coefficients show that people in Essen and Melbourne were more fearful compared to people in Cologne and Brisbane, respectively.

Model 2 focused on the central research question of this paper about the nature of the $\mathrm{P} \times \mathrm{E}$ interaction. A significant negative coefficient for the multiplicative term between linear age and neighbourhood disadvantage suggests that this $\mathrm{P} \times \mathrm{E}$ interaction indeed exists and has the same direction in both countries. This conclusion is supported by an increased model fit, both in terms of a slight increase in individual-level explained variance and a slight decrease in AIC, and despite the absence of a significant random slope of age. The negative coefficient indicates that a higher value on one variable decreases the effect of the other variable. Thus, the results support hypothesis H1b that the effect of neighbourhood disadvantage on fear of crime is weaker in higher age.

As interaction effects are notoriously difficult to understand, we visualised the predicted effects on localised fear in three graphs. Figure 2 illustrates the varying effects of neighbourhood disadvantage on fear at different ages of respondents, and, as interactions are symmetrical and can be viewed from both angles, Figure 3 illustrates the varying effects of age on fear at different levels of neighbourhood disadvantage. Technically, both figures are graphical representations of the marginal means of the outcome variable at defined values of the two predictors involved in the interaction, controlling for all other effects in the model.

Figure 2 shows for both countries that localised fear increased with social disadvantage at all ages, and that older people, and in particular the very old, reported 
more fear than younger people in most kinds of neighbourhoods. Looking at younger ages (25 years up to 45 years) in Australia, fear increased from a low of just under 0.25 (on a scale between 0 and 1) in the least disadvantaged neighbourhoods to a high of just under 0.50 in the most disadvantaged neighbourhoods. Likewise, for younger people in Germany, fear increased from a low of around 0.25 in the least disadvantaged neighbourhoods to a high of around 0.60 in the most disadvantaged neighbourhoods. Note that in both countries, fear on average roughly doubled comparing the extreme poles of neighbourhood social conditions, irrespectively of the large difference in the range of unemployment rates in Australia (approximately 0-8\%) and Germany (approximately 2-28\%).

The $\mathrm{P} \times \mathrm{E}$ interaction is expressed in Figure 2 in the decreasing steepness of the slope of neighbourhood disadvantage at age 65 and in particular 85 years. Thus, older people's fear was less strongly associated with neighbourhood disadvantage. At the same time, older people were considerably more fearful than younger ages in better-off neighbourhoods and, reversely, younger ages were as fearful (almost in Australia, actually in Germany) as older people in the most disadvantaged neighbourhoods.

Figure 3 illustrates the same $\mathrm{P} \times \mathrm{E}$ interaction from a reversed angle. As the $x$-axis now represents age, one can clearly see the curvilinear increase of localised fear with age. In the least disadvantaged neighbourhoods, fear started at a low level at young age and increased considerably with age, and more forcefully in older age. In other words, younger people were considerably less fearful in better-off neighbourhoods than their old-age neighbours. In contrast, residents in the most disadvantaged neighbourhoods were all very fearful, no matter their age. One can infer from this that younger people react more forcefully to neighbourhood social conditions in expressing fear, whereas old people show high levels of fear irrespectively of neighbourhood contexts. Neighbourhood social conditions matter more for younger than for older people's localised fear. Especially the very high fear levels of old residents in better-off neighbourhoods suggest that their safety perceptions are out of proportion with real neighbourhood conditions, and hence must be influenced by other factors peculiar to their age group.

Figure 4 takes yet another angle on the $\mathrm{P} \times \mathrm{E}$ interaction. This graph plots the marginal effects of neighbourhood disadvantage on localised fear by age. The marginal effects represent the coefficient at specific values of the other variable involved in the interaction. The reduction with age of the effect of neighbourhood disadvantage is very similar in both countries: at age 25, the effect is around 0.15 and decreases in a curvilinear fashion to less than 0.07 at age 90 . As the histograms in Figure 4 indicate, we have sufficient data to compute reliably the marginal effects of unemployment rates along the age spectrum.

The contour plots (Figure 5) offer a more nuanced perspective on the $\mathrm{P} \times \mathrm{E}$ interactions and serve as an additional check of the robustness of our findings in Model 2 (Hainmueller et al., 2019). ${ }^{3}$ They should be interpreted like topographic maps with age and neighbourhood disadvantage on the axes. Higher (brighter) areas indicate more fear. Faster colour changes imply steeper gradients. We interpret these results as follows: first, holding neighbourhood disadvantage or age constant, i.e. looking strictly vertically (the increase of fear with age holding neighbourhood disadvantage constant) or horizontally (the increase of fear with 


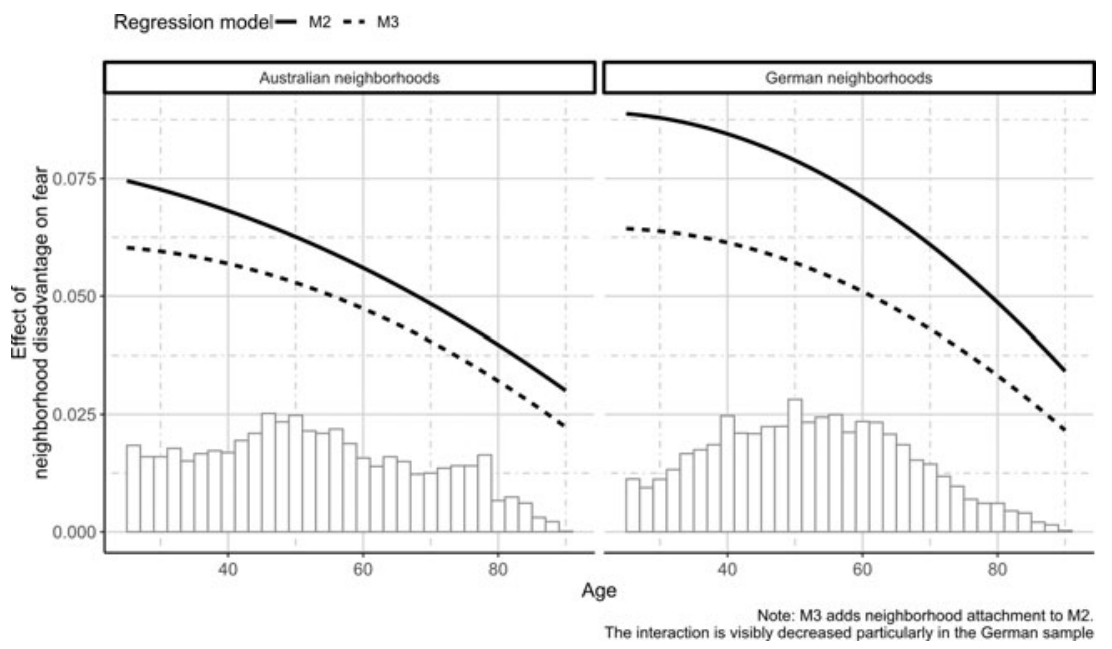

Figure 4. Marginal effects of neighbourhood social disadvantage depending on age.

Notes: Model 3 (M3) adds neighbourhood attachment to Model 2 (M2). The interaction is visibly decreased, particularly in the German sample.

neighbourhood disadvantage holding age constant), localised fear of crime increased with age and, more strongly, with neighbourhood disadvantage; second, the slope of neighbourhood disadvantage on fear was greater for younger than for older people in Germany (see the contour lines). In Australia, however, older people reacted more strongly to changes in social disadvantage at the beginning of the scale (roughly from 0 to $2 \%$ of neighbourhood unemployment), while the increase of fear with social disadvantage was stronger for younger people between 3 and 5 per cent of neighbourhood unemployment. After that, the steeper slope for younger people is reduced again. Third, the interaction surface was fairly smooth, without drastic humps, wrinkles or holes. This supports our modelling approach of nonlinear but monotonically decreasing neighbourhood effects depending on age (and, due to the symmetry of interaction effects, also vice vers). The small deviations from these changing effects (discussed as "second" in this paragraph) do not impair our primary finding of a noticeable $\mathrm{P} \times \mathrm{E}$ interaction in both countries.

As a final analytical step, we test hypothesis $\mathrm{H} 2$ that the reduced impact of neighbourhood disadvantage on localised fear of older residents is, among other things, due to their higher level of neighbourhood attachment which may act as a buffer to adverse environmental influences. As outlined above, the potential underlying mechanism assumes that older people feel more attached to their neighbourhood and, therefore, consciously or unconsciously ignore fear-provoking neighbourhood characteristics. While neighbourhood attachment did significantly increase with age in both countries, the bivariate correlation was rather weak $\rho=0.09$ in Germany, $\rho=0.08$ in Australia with signs of curvilinearity), limiting the potential scope of mediation effects.

Model 3 shows, first of all, that neighbourhood attachment, in fact, had a very strong association with fear. Very low attachment (compared to a middle category) was associated with an increase of localised fear by 0.24 scale points in Germany 


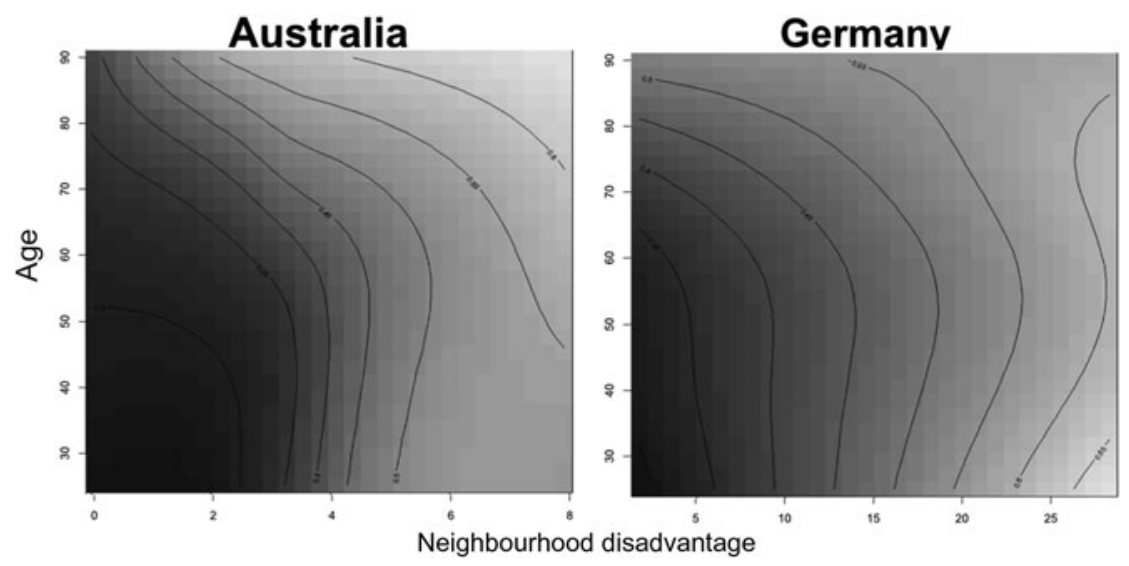

Figure 5. Interaction surface of age and neighbourhood social disadvantage predicting fear.

and 0.20 in Australia, and very high attachment (again, compared to a middle category) decreased fear by 0.08 scale points in Germany and 0.19 scale points in Australia. Thus, neighbourhood attachment was by far the strongest predictor of localised fear. The strong impact was also reflected by an increase of explained individual-level variance from approximately 10 to 15.7 per cent in Germany and from approximately 9 to 17.3 per cent in Australia. It is important to regard this association between neighbourhood safety perceptions and attachment as bi-directional: residents who are strongly attached to their neighbourhood feel safer, and at the same time residents who feel very unsafe in their neighbourhood surely are less attached to it.

The mediation hypothesis that neighbourhood attachment accounts for the interaction between age and neighbourhood disadvantage received modest support. The multiplicative interaction term (age $\times$ neighbourhood disadvantage) decreased by around a fifth in both countries between Models 2 and 3, but the resulting differences of coefficients did not reach significance. Thus, neighbourhood attachment can explain some part but not the bulk of this $\mathrm{P} \times \mathrm{E}$ interaction.

In additional models, we alternatively tested for the interaction between violent crime rates and age (not shown in Table 5, results available on request). There was no interaction effect in Germany and only a marginally significant positive interaction with the quadratic age term $(p<0.05)$ in Australia, indicating a small curvilinear interaction; younger as well as older respondents showed slightly stronger effects with regard to violent crime rates than middle-aged respondents. This finding, albeit not as robust as our main finding, merits further analysis.

\section{Summary and discussion}

It is a widely shared assumption in ageing research that 'where people live ... makes a difference' (Gerstorf et al., 2010) and, in particular, that older people's wellbeing becomes more susceptible to environmental adversities because physical and mental vulnerabilities increase with age (Annear et al., 2014; Cagney and Cornwell, 
2018; Wahl and Gerstorf, 2018). Crime and perceptions of insecurity are one facet of local environments which may cause stress and negatively impact the wellbeing of older residents. Research has for decades discussed the heightened susceptibility of older people to fear of crime against the backdrop of age-related vulnerabilities (Greve et al., 2017). The 'environmental docility hypothesis' proposed by Lawton and Simon (1968) has been very influential in promoting the view more generally that age-related reductions in individual competencies increase the significance of external conditions for wellbeing.

However, the empirical evidence substantiating this hypothesis is not conclusive as few studies have investigated the impact of environmental conditions on wellbeing differentiated by age groups, instead largely focusing on age-restricted samples (Yen et al., 2009; De Donder et al., 2013; Annear et al., 2014).

This paper contributes to filling this gap by analysing the age-specific association of fear of crime and adverse neighbourhood conditions in two separate community surveys of the general adult population in 435 neighbourhoods in two German and two Australian cities. Using the unemployment rate as a lead indicator of problematic neighbourhood conditions and employing multi-level modelling, we showed that older adults are, in fact, not more, but less susceptible to neighbourhood conditions with regard to fear of crime, quite contrary to the prevailing view.

Overall, neighbourhood disadvantage accounted for around two-thirds of the between-neighbourhood variance in feelings of insecurity in both countries, despite considerable differences in the local concentrations of social disadvantage in German and Australian cities. Compared to individual-level socio-demographic variables except gender, neighbourhood disadvantage was the strongest predictor of fear of crime in both countries, and considerably stronger than violent crime rate which was only weakly associated with fear. But the cross-level interaction between individual age and neighbourhood disadvantage revealed that the size of this effect dropped by around half from the youngest ( 25 years) to the oldest age (90 years) in both samples (see Figure 4). Thus, older people's fear was considerably less strongly associated with neighbourhood disadvantage. Consequently, younger people were almost as fearful as older people in the most disadvantaged neighbourhoods (see Figure 2). Our findings parallel those of a very early study by Maxfield (1984; 246; McGarrell et al., 1997) who concluded that 'everyone is more afraid' in the most problematic neighbourhoods. On the flipside, we found older people to be considerably more fearful than younger ages in better-off neighbourhoods.

Taken together, these findings suggest that older people's safety perceptions tend to be less connected with objective neighbourhood conditions in comparison to younger ages, and hence must be influenced by other factors peculiar to their age group. We tested and found limited evidence for a mediating effect of neighbourhood attachment on the relation between neighbourhood disadvantage and fear of crime, in line with the notion of Wahl and Gerstorf (2018: 163) that a strong 'sense of place identity' protects older residents against external adversities. However, while place attachment may explain the mitigated association between older age and fear in the most disadvantaged neighbourhoods, it cannot account for the higher levels of fear of older people (relative to younger ages) in middle-class neighbourhoods. 
Our findings may have important implications for prevention. Programmes for improving the subjective security of older people primarily geared at disadvantaged neighbourhoods may miss a relevant target group: older people in middle-class neighbourhoods.

Data limitations prevent us from elaborating our analysis further. The crossnational comparative design restricts the catalogue of available variables both on the individual and on the neighbourhood level. Doubts about the ambiguous meanings of the single item measuring localised fear calls for more fine-grained analyses of the cognitive, affective and behavioural dimensions of fear of crime. Unfortunately, these variables were available only in the German study where analogue analyses support the findings above (Köber, 2018: chap. 5.7). To measure neighbourhood conditions, we relied on the unemployment rate as a single indicator of social disadvantage, thus missing other potential environmental influences. Nevertheless, it accounts for 69 and 58 per cent of the neighbourhood-level variation of fear of crime in Germany and Australia, respectively, once more underlining the pivotal role of social inequality in shaping collective urban perceptions (Sampson, 2009). In contrast, crime rates showed relatively weak effects on local insecurities, in line with many previous studies (Oberwittler, 2008; Drakulich, 2013, 2015).

The interplay of fear of crime, physical health and activity patterns, and neighbourhood conditions is a worthwhile direction for future research. Limited data availability prevented us from digging deeper by including direct measurements of physical or mental vulnerabilities which are seen as major proximal influences on wellbeing in older age (Schilling et al., 2018; Wahl and Gerstorf, 2018). The association of physical health and fear of crime is well-documented in the literature (Greve, 1998; Cossman and Rader, 2011; Köber, 2018). Also, and closely related to health, we lack information on the activity patterns and outdoor routines of respondents which may hold a clue to our findings. Mobility and outdoor activities become more constricted with age-related reductions in physical health (Mendes de Leon et al., 2009; Tucker-Seeley et al., 2009; Annear et al., 2014). Especially in very old age and in cases of serious and chronic health impairments, people spend most of their daytime at home, which increasingly replaces the outside world as a salient environment (Oswald et al., 2005; Schilling et al., 2018). This 'insideness' may shield older people with reduced mobility from exposure to outside neighbourhood conditions, and their physical impairments may account for increased levels of perceived insecurity irrespective of neighbourhood contexts. Physical health and, in particular, activity and mobility patterns should be considered in future studies of neighbourhood influences on wellbeing and security perceptions across adult lifestages.

\section{Notes}

1 Age-specific response rates could be computed in the German study because the sampling was based on a population register.

2 Model 3 did not converge in Australia or in Germany with a random slope for age and age squared. In the converging models, the random slopes did not improve model fit according to the likelihood ratio test. Contrary to what Heisig and Schaeffer (2019) found, the standard errors (SE) of the interaction effects were only slightly larger when random age slopes were included into the model (in the Australian sub-sample: neighbourhood disadvantage $\times$ age $=-0.035(\mathrm{SE}=0.012)$ and neighbourhood disadvantage $\times$ age squared $=-0.006(\mathrm{SE}=0.012)$ including the random slope compared to $-0.036(\mathrm{SE}=0.011)$ and -0.006 
$(\mathrm{SE}=0.011)$, respectively, without random slope). The same model for the German sub-sample with a random slope had a singular fit. In their discussion of cross-level interactions, Snijders and Bosker (2012: 82, 105) stress that the random slope of the individual-level part of an assumed interaction effect is often found to be non-significant while the test of the cross-level interaction is significant, due to a higher statistical power of the latter. They recommend considering the cross-level interaction in the absence of significant random slopes if it is based on strong theory.

3 We re-estimated Model 2 as a generalised additive model (Wood, 2017) which introduces flexibility to the interaction of interest: the effects of age and neighbourhood disadvantage are not forced to change at a constant rate (i.e. the coefficients of the interaction term) but are fitted more freely to the data. Hainmueller $e t$ al. (2019) recently argued that analysts should avoid interpreting wide numerical intervals where actually no sufficient numbers of observations with a satisfactory degree of variation exist. More important for this analysis is their second point, according to which marginal effects are generally assumed to be linear: the change of the effect of one variable on the outcome due to the other interacting variable takes place at a constant rate. We used the tensor product method with the default number of knots to estimate the interaction surface (Wood, 2017). This statistical technique is superior to linear models due to their high flexibility while remaining interpretable in contrast to other flexible machine learning approaches like neural nets.

\section{References}

Ai C and Norton EC (2003) Interaction terms in logit and probit models. Economics Letters 80, 123-129.

Aiken LS, West SG and Reno RR (1991) Multiple Regression: Testing and Interpreting Interactions. Thousand Oaks, CA: Sage.

Alper M and Chappell AT (2012) Untangling fear of crime: a multi-theoretical approach to examining the causes of crime-specific fear. Sociological Spectrum 32, 346-363.

Annear M, Keeling S, Wilkinson T, Cushman G, Gidlow B and Hopkins H (2014) Environmental influences on healthy and active ageing: a systematic review. Ageing \& Society 34, 590-622.

Baltes PB and Smith J (2003) New frontiers in the future of aging: from successful aging of the young old to the dilemmas of the fourth age. Gerontology 49, 123-135.

Barton MS, Weil F, Jackson M and Hickey DA (2017) An investigation of the influence of the spatial distribution of neighborhood violent crime on fear of crime. Crime \& Delinquency 63, 1757-1776.

Bates D, Mächler M, Bolker B and Walker S (2015) Fitting linear mixed-effects models using lme4. Journal of Statistical Software 67, 1-48.

Berry WD, Golder M and Milton D (2012) Improving tests of theories positing interaction. Journal of Politics 74, 653-671.

Boschman S (2018) Individual differences in the neighbourhood level determinants of residential satisfaction. Housing Studies 33, 1127-1143.

Brambor T, Clark WR and Golder M (2006) Understanding interaction models: improving empirical analyses. Political Analysis 14, 63-82.

Brunton-Smith I and Jackson J (2012) Urban fear and its roots in place. In Ceccato V (ed.), The Urban Fabric of Crime and Fear. Dordrecht, The Netherlands: Springer Science+Business Media, pp. 55-82.

Brunton-Smith I and Sturgis P (2011) Do neighborhoods generate fear of crime? An empirical test using the British Crime Survey. Criminology 49, 331-369.

Brunton-Smith I, Jackson J and Sutherland A (2014) Bridging structure and perception. British Journal of Criminology 54, 503-526.

Cagney KA and Cornwell EY (2018) Place, aging, and health. In Hayward MD and Majmundar MK (eds). Future Directions for the Demography of Aging: Proceedings of a Workshop. Washington, DC: National Academies Press, pp. 131-155.

Chang L-Y, Wang M-Y and Tsai P-S (2016) Neighborhood disadvantage and physical aggression in children and adolescents: a systematic review and meta-analysis of multilevel studies. Aggressive Behavior 42, 441-454.

Clemente F and Kleiman MB (1977) Fear of crime in the United States: a multivariate analysis. Social Forces 56, 519-531.

Cobbina JE, Miller J and Brunson RK (2008) Gender, neighborhood danger, and risk-avoidance strategies among urban African-American youths. Criminology 46, 673-709. 
Cohen P, Cohen J, Aiken LS and West SG (1999) The problem of units and the circumstance for pomp. Multivariate Behavioral Research 34, 315-346.

Collins RE (2016) Addressing the inconsistencies in fear of crime research: a meta-analytic review. Journal of Criminal Justice 47, 21-31.

Collins CR and Guidry S (2018) What effect does inequality have on residents' sense of safety? Exploring the mediating processes of social capital and civic engagement. Journal of Urban Affairs 40, 1009-1026.

Cossman JS and Rader NE (2011) Fear of crime and personal vulnerability: examining self-reported health. Sociological Spectrum 31, 141-162.

Cossman JS, Porter JR and Rader NE (2016) Examining the effects of health in explaining fear of crime: a multi-dimensional and multi-level analysis. American Journal of Criminal Justice 41, 565-582.

Cramm JM, Dijk HM van and Nieboer AP (2013) The importance of neighborhood social cohesion and social capital for the well being of older adults in the community. The Gerontologist 53, 142-152.

De Donder L, De Witte N, Buffel T, Dury S and Verté D (2012) Social capital and feelings of unsafety in later life: a study on the influence of social networks, place attachment, and civic participation on perceived safety in Belgium. Research on Aging 34, 425-448.

De Donder L, Buffel T, Dury S, De Witte N and Verté D (2013) Perceptual quality of neighbourhood design and feelings of unsafety. Ageing \& Society 33, 917-937.

Drakulich KM (2013) Perceptions of the local danger posed by crime: race, disorder, informal control, and the police. Social Science Research 42, 611-632.

Drakulich KM (2015) Social capital, information, and perceived safety from crime: the differential effects of reassuring social connections and vicarious victimization. Social Science Quarterly 96, 176-190.

Easton M (2013) Fear of Crime and Older Adults: A Metanarrative Review of the Literature (Master's thesis). Simon Fraser University, Burnaby, (British Columbia), Canada.

Eriksson M and Ng N (2015) Neighbourhood social capital and women's self-rated health: is there an age pattern? A multi-level study from northern Sweden. In Nyqvist F and Forsman AK (eds), Social Capital as a Health Resource in Later Life: The Relevance of Context. Dordrecht, The Netherlands: Springer, pp. 127-143.

Farrall S, Bannister J, Ditton J and Gilchrist E (1997) Questioning the measurement of the 'fear of crime': findings from a major methodological study. British Journal of Criminology 37, 658-679.

Fattah EA and Sacco VF (1989) Crime and Victimization of the Elderly. New York, NY: Springer.

Ferraro KF and LaGrange RL (1987) The measurement of fear of crime. Sociological Inquiry 57, 70-97.

Ferraro KF and LaGrange RL (1992) Are older people most afraid of crime? Reconsidering age differences in fear of victimization. Journal of Gerontology 47, S233-S244.

Fox J (2003) Effect displays in R for generalised linear models. Journal of Statistical Software 8, 1-27.

Frederiksen H, Hjelmborg J, Mortensen J, Mcgue M, Vaupel JW and Christensen K (2006) Age trajectories of grip strength: cross-sectional and longitudinal data among 8,342 Danes aged 46 to 102. Annals of Epidemiology 16, 554-562.

Gabriel U and Greve W (2003) The psychology of fear of crime. Conceptual and methodological perspectives. British Journal of Criminology 43, 600-614.

Garcia RM, Taylor RB and Lawton BA (2007) Impacts of violent crime and neighborhood structure on trusting your neighbors. Justice Quarterly 24, 679-704.

Gelman A (2007) Scaling regression inputs by dividing by two standard deviations. Statistics in Medicine 27, 2865-2873.

Gerstner D and Oberwittler D (2016) Bevölkerungsbefragung 'Zusammenleben und Sicherheit in Köln/ Essen'-Methodenbericht. Freiburg, Germany: Max-Planck-Institut für ausländisches und internationales Straftrecht.

Gerstner D, Wickes R and Oberwittler D (2019) Collective efficacy in Australian and German neighborhoods: testing cross-cultural measurement equivalence and structural correlates in a multi-level SEM framework. Social Indicators Research 144, 1151-1177.

Gerstorf D, Ram N, Goebel J, Schupp J, Lindenberger U and Wagner GG (2010) Where people live and die makes a difference: individual and geographic disparities in well-being progression at the end of life. Psychology and Aging 25, 661-676.

Gerstorf D, Hülür G, Drewelies J, Eibich P, Duezel S, Demuth I, Ghisletta P, Steinhagen-Thiessen E, Wagner GG and Lindenberger $\mathbf{U}$ (2015) Secular changes in late-life cognition and well-being: towards a long bright future with a short brisk ending? Psychology and Aging 30, 301-310. 
Gibson CL, Zhao J, Lovrich NP and Gaffney MJ (2002) Social integration, individual perceptions of collective efficacy, and fear of crime in three cities. Justice Quarterly 19, 537-564.

Goldsmith J and Tomas NE (1974) Crimes against the elderly: a continuing national crisis. Aging 236, 10-13.

Gray E, Grasso M, Farrall S, Jennings W and Hay C (2018) Political socialization, worry about crime and antisocial behaviour: an analysis of age, period and cohort effects. British Journal of Criminology 59, 435-460.

Greene W (2010) Testing hypotheses about interaction terms in nonlinear models. Economics Letters 107, 291-296.

Greve W (1998) Fear of crime among the elderly: foresight, not fright. International Review of Victimology 5, 277-309.

Greve W, Leipold B and Kappes C (2017) Fear of crime in old age: a sample case of resilience? Journals of Gerontology: Psychological Sciences and Social Sciences 73B, 1224-1232.

Häfele J (2013) Die Stadt, das Fremde und die Furcht vor Kriminalität. Wiesbaden, Germany: Springer VS.

Hainmueller J, Mummolo J and Xu Y (2019) How much should we trust estimates from multiplicative interaction models? Simple tools to improve empirical practice. Political Analysis 27, 163-192.

Hale C (1996) Fear of crime: a review of the literature. International Review of Victimology 4, 79-150.

Ham M van, Manley D, Bailey N, Simpson L and Maclennan D (2012) Neighbourhood Effects Research: New Perspectives. Dordrecht, The Netherlands: Springer.

Hank K, Jürges H, Schupp J and Wagner GG (2009a) Isometrische Greifkraft und sozialgerontologische Forschung. Zeitschrift für Gerontologie und Geriatrie 42, 117-126.

Hank K, Jürges H, Wagner GG and Schupp J (2009b) Über Survey-fragen hinaus: Isometrische Greifkraftmessung in SHARE und SOEP. In Börsch-Supan A, Hank K, Jürges H and Schröder M (eds), 50plus in Deutschland und Europa. Wiesbaden, Germany: Springer VS, pp. 175-192.

Heisig JP and Schaeffer M (2019) Why you should always include a random slope for the lower-level variable involved in a cross-level interaction. European Sociological Review 35, 258-279.

Hinkle JC (2013) The relationship between disorder, perceived risk, and collective efficacy: a look into the indirect pathways of the broken windows thesis. Criminal Justice Studies 26, 408-432.

Hipp J (2010) What is the 'neighbourhood' in neighbourhood satisfaction? Comparing the effects of structural characteristics measured at the micro-neighbourhood and tract levels. Urban Studies 47, 2517-2536.

Hipp JR (2011) Violent crime, mobility decisions, and neighborhood racial/ethnic transition. Social Problems 58, 410-432.

Hipp JR (2013) Assessing crime as a problem: the relationship between residents' perception of crime and official crime rates over 25 years. Crime \& Delinquency 59, 616-648.

Hummelsheim D, Hirtenlehner H, Jackson J and Oberwittler D (2011) Social insecurities and fear of crime: a cross-national study on the impact of welfare state policies on crime-related anxieties. European Sociological Review 27, 327-345.

Jackson J (2004) Experience and expression: Social and cultural significance in the fear of crime. British Journal of Criminology 44, 946-966.

Jackson J (2009) A psychological perspective on vulnerability in the fear of crime. Psychology, Crime \& Law 15, 365-390.

Jackson J and Stafford M (2009) Public health and fear of crime a prospective cohort study. British Journal of Criminology 49, 832-847.

Janssen H, Oberwittler D and Gerstner D (2019) Dissecting disorder perceptions: neighborhood structure and the moderating role of interethnic contact and xenophobic attitudes. International Criminal Justice Review. Available online doi: 10.1177/1057567719896020.

Kappes C, Greve W and Hellmers S (2013) Fear of crime in old age: precautious behaviour and its relation to situational fear. European Journal of Ageing 10, 111-125.

Killias M (1990) Vulnerability: towards a better understanding of a key variable in the genesis of fear of crime. Violence and Victims 5, 97-108.

Köber G (2018) A Dynamic and Relational Perspective on Vulnerability and Fear of Crime. The Role of Physical, Psychological, and Social Factors as well as Life Events and Neighborhood Contexts Using a Between-Within Approach (PhD thesis). University of Freiburg, Freiburg, Germany.

Köber G and Oberwittler D (2019) How older people became less afraid of crime - an age-period-cohort analysis using repeated cross-sectional survey data. Social Science Research 79, 211-225. 
Kraus MW, Piff PK, Mendoza-Denton R, Rheinschmidt ML and Keltner D (2012) Social class, solipsism, and contextualism: how the rich are different from the poor. Psychological Review 119, 546-572.

Kreuter F (2002) Kriminalitätsfurcht: Messung und methodische Probleme. Opladen, Germany: Leske + Budrich.

Kronauer M and Siebel W (2013) Polarisierte Städte: Soziale Ungleichheit als Herausforderung für die Stadtpolitik. Frankfurt am Main, Germany: Campus.

Kullberg A, Timpka T, Svensson T, Karlsson N and Lindqvist K (2010) Does the perceived neighborhood reputation contribute to neighborhood differences in social trust and residential wellbeing? Journal of Community Psychology 38, 591-606.

LaGrange RL and Ferraro KF (1989) Assessing age and gender differences in perceived risk and fear of crime. Criminology 27, 697-720.

Laméris J, Hipp JR and Tolsma J (2018) Perceptions as the crucial link? The mediating role of neighborhood perceptions in the relationship between the neighborhood context and neighborhood cohesion. Social Science Research 72, 53-68.

Lawton MP (1990) Residential environment and self-directedness among older people. American Psychologist 45, 638-640.

Lawton B (2018) Deciding on the 'appropriate' unit of analysis. Practical considerations in environmental criminology. In Bruinsma G and Johnson D (eds), The Oxford Handbook of Environmental Criminology. Oxford: Oxford University Press, pp. 177-189.

Lawton MP and Simon B (1968) The ecology of social relationships in housing for the elderly. The Gerontologist 8, 108-115.

Lindström M, Lindström C, Moghadassi M and Merlo J (2006) Social capital and neo-materialist contextual determinants of sense of insecurity in the neighbourhood: a multilevel analysis in southern Sweden. Health \& Place 12, 479-489.

Lüdemann C (2006) Kriminalitätsfurcht im urbanen Raum. KZfSS Kölner Zeitschrift für Soziologie und Sozialpsychologie 58, 285-306.

Magnusson D and Stattin H (2006) The person in context: a holistic-interactionistic approach. In Damon W and Lerner RM (eds), Handbook of Child Psychology. Hoboken, NJ: Wiley, pp. 400-464.

Markowitz FE, Bellair PE, Liska AE and Liu J (2001) Extending social disorganization theory: modeling the relationships between cohesion, disorder, and fear. Criminology 39, 293-319.

Maxfield MG (1984) The limits of vulnerability in explaining fear of crime: a comparative neighborhood analysis. Journal of Research in Crime and Delinquency 21, 233-250.

McCoy H, Wooldredge JD, Cullen FT, Dubeck PJ and Browning SL (1996) Lifestyles of the old and not so fearful: life situation and older persons' fear of crime. Journal of Criminal Justice 24, 191-205.

McGarrell EF, Giacomazzi AL and Thurman QC (1997) Neighborhood disorder, integration, and the fear of crime. Justice Quarterly 14, 479-500.

McNeeley S and Stutzenberger A (2013) Victimization, risk perception, and the desire to move. Victims \& Offenders 8, 446-464.

Mellgren C (2011) What's Neighbourhood Got to Do with It? (PhD thesis). University of Malmö, Malmö, Sweden.

Mendes de Leon CF, Cagney KA, Bienias JL, Barnes LL, Skarupski KA, Scherr PA and Evans DA (2009) Neighborhood social cohesion and disorder in relation to walking in community-dwelling older adults: a multilevel analysis. Journal of Aging and Health 21, 155-171.

Michael YL and Yen IH (2014) Aging and place - neighborhoods and health in a world growing older. Journal of Aging and Health 26, 1251-1260.

Mood C (2010) Logistic regression: why we cannot do what we think we can do, and what we can do about it. European Sociological Review 26, 67-82.

Mulry MH (2014) Measuring undercounts for hard-to-survey groups. In Tourangeau R, Edwards B, Johnson T, Wolter $\mathrm{K}$ and Bates N (eds), Hard-to-survey Populations. Cambridge: Cambridge University Press, pp. 37-57.

Mustered S, Murie A and Kestellot C (2006) Neighborhoods of Poverty: Urban Social Exclusion and Integration in Europe. London: Macmillan.

Narula SC (1979) Orthogonal polynomial regression. International Statistical Review/Revue Internationale de Statistique 46, 31-36. 
Oberwittler D (2008) Armut macht Angst-Ansätze einer sozialökologischen Interpretation der Kriminalitätsfurcht. In Groenemeyer A and Wieseler S (eds), Soziologie sozialer Probleme und sozialer Kontrolle: Realitäten, Repräsentationen und Politik. Wiesbaden, Germany: Springer VS, pp. 215-230.

Oberwittler D and Wikström P-OH (2009) Why small is better: advancing the study of the role of behavioral contexts in crime causation. In Weisburd D, Bernasco W and Bruinsma G (eds), Putting Crime in Its Place. New York, NY: Springer Science+Business Media, pp. 35-59.

Oberwittler D, Janssen HJ and Gerstner D (2017) Unordnung und Unsicherheit in großstädtischen Wohngebieten - Die überschätzte Rolle von 'Broken Windows' und die Herausforderungen ethnischer Diversität. Soziale Probleme 28, 181-205.

Organisation for Economic Co-operation and Development (OECD) (2018) Divided Cities. Paris: OECD Publishing.

Organisation for Economic Co-operation and Development (OECD) (2019) Quarterly National Accounts: GDP Per Capita. Available at https://stats.oecd.org/.

Oswald F, Hieber A, Wahl H-W and Mollenkopf H (2005) Ageing and person-environment fit in different urban neighbourhoods. European Journal of Ageing 2, 88-97.

Oswald F, Wahl H-W, Naumann D, Mollenkopf H and Hieber A (2006) The role of the home environment in middle and late adulthood. In Wahl H-W, Brenner H, Mollenkopf H, Rothenbacher D and Rott C (eds), The Many Faces of Health, Competence and Well-being in Old Age: Integrating Epidemiological, Psychological and Social Perspectives. Dordrecht, The Netherlands: Springer, pp. 7-24.

Permentier M, Bolt G and Ham M van (2011) Determinants of neighbourhood satisfaction and perception of neighbourhood reputation. Urban Studies 48, 977-996.

R Core Team (2016) R: A Language and Environment for Statistical Computing. Vienna: R Foundation for Statistical Computing.

Reuband K-H (1989) Die Kriminalitätsfurcht der Bundesbürger 1965-1987: Veränderungen unter dem Einfluß sich wandelnder Geschlechterrollen. Zeitschrift für Soziologie 18, 470-476.

Reuband K-H (2000) Der Standardindikator zur Messung der Kriminalitätsfurcht. In 'skandalöser Weise' unspezifisch und in der Praxis dennoch brauchbar? Monatsschrift für Kriminologie und Strafrechtsreform 83, 185-195.

Robert SA and Li LW (2001) Age variation in the relationship between community socioeconomic status and adult health. Research on Aging 23, 234-259.

Robinson JB, Lawton BA, Taylor RB and Perkins DD (2003) Multilevel longitudinal impacts of incivilities: fear of crime, expected safety, and block satisfaction. Journal of Quantitative Criminology 19, 237-274.

Ross CE, Mirowsky J and Pribesh S (2001) Powerlessness and the amplification of threat: neighborhood disadvantage, disorder, and mistrust. American Sociological Review 66, 568-591.

Sampson RJ (2009) Disparity and diversity in the contemporary city: social (dis)order revisited. British Journal of Sociology 60, 1-31.

Sampson RJ (2018) Neighbourhood effects and beyond: explaining the paradoxes of inequality in the changing American metropolis. Urban Studies 56, 3-32.

Sargeant E, Liu Y, John NS, Hong NF, Huu T, Chen J and Mazerolle L (2017) Social capital and fear of crime in Brisbane. Journal of Sociology 53, 637-652.

Sarkar D (2008) Lattice: Multivariate Data Visualization with R. New York, NY: Springer.

Scarborough BK, Like-Haislip TZ, Novak KJ, Lucas WL and Alarid LF (2010) Assessing the relationship between individual characteristics, neighborhood context, and fear of crime. Journal of Criminal Justice 38, $819-826$.

Schieman S (2009) Residential stability, neighborhood racial composition, and the subjective assessment of neighborhood problems among older adults. The Sociological Quarterly 50, 608-632.

Schilling OK, Deeg DJ and Huisman M (2018) Affective well-being in the last years of life: the role of health decline. Psychology and Aging 33, 739-753.

Sharkey P and Faber JW (2014) Where, when, why, and for whom do residential contexts matter? Moving away from the dichotomous understanding of neighborhood effects. Annual Review of Sociology 40, 559-579.

Sharp G (2018) Eclipsing community? Neighborhood disadvantage, social mechanisms, and neighborly attitudes and behaviors. City \& Community 17, 615-635. 
Skogan WG (2015) Disorder and decline: the state of research. Journal of Research in Crime and Delinquency 52, 464-485.

Skogan WG and Maxfield MG (1981) Coping with Crime: Individual and Neighborhood Reactions. Beverly Hills, CA: Sage.

Snedker KA (2015) Neighborhood conditions and fear of crime a reconsideration of sex differences. Crime \& Delinquency 61, 45-70.

Snijders TAB and Bosker RJ (2012) Multilevel Analysis: An Introduction to Basic and Advanced Multilevel Modeling, 2nd Edn. London: Sage.

Sturgis P, Roberts C and Smith P (2014) Middle alternatives revisited: how the neither/nor response acts as a way of saying 'I don't know'? Sociological Methods \& Research 43, 15-38.

Taylor RB (1995) The impact of crime on communities. Annals of the American Academy of Political and Social Science 539, 28-45.

Taylor RB (2001) Breaking Away from Broken Windows: Baltimore Neighborhoods and the Nationwide Fight Against Crime, Grime, Fear, and Decline. Boulder, CO: Westview Press.

Time (1976) The elderly: prisoners of fear. Time 108, 21.

Tolsma J, Meer T van der and Gesthuizen M (2009) The impact of neighbourhood and municipality characteristics on social cohesion in the Netherlands. Acta Politica 44, 286-313.

Tucker-Seeley RD, Subramanian S, Li Y and Sorensen G (2009) Neighborhood safety, socioeconomic status, and physical activity in older adults. American Journal of Preventive Medicine 37, 207-213.

UNESCO Institute for Statistics (2006) International Standard Classification of Education: ISCED 1997. Montreal: UNESCO Institute for Statistics.

United Nations Development Programme (2015) Human Development Report 2015: Work for Human Development. New York, NY: United Nations Development Programme.

Wahl H-W and Gerstorf D (2018) A conceptual framework for studying COntext Dynamics in Aging (CODA). Developmental Review 50, 155-176.

Wahl H-W, Mollenkopf H, Oswald F and Claus C (2007) Environmental aspects of quality of life in old age: conceptual and empirical issues. In Mollenkopf $\mathrm{H}$ and Walker A (eds), Quality of Life in Old Age: International and Multi-disciplinary Perspectives. Dordrecht, The Netherlands: Springer, pp. 101-122.

Wahl H-W, Iwarsson S and Oswald F (2012) Aging well and the environment: toward an integrative model and research agenda for the future. The Gerontologist 52, 306-316.

Wickes R (2017) Social disorganization theory: its history and relevance to crime prevention. In Teasdale B and Bradley MS (eds), Preventing Crime and Violence. Cham, Switzerland: Springer, pp. 57-66.

Wickham H (2016) ggplot2: Elegant Graphics for Data Analysis, 2nd Edn. New York, NY: Springer.

Wikström P-OH (2004) Crime as alternative. Towards a cross-level situational action theory of crime causation. In McCord J (ed.), Beyond Empiricism: Institutions and Intentions in the Study of Crime. New Brunswick, NJ: Transaction Publishers, pp. 1-37.

Wilson-Genderson M and Pruchno R (2013) Effects of neighborhood violence and perceptions of neighborhood safety on depressive symptoms of older adults. Social Science \& Medicine 85, 43-49.

Wood SN (2017) Generalized Additive Models: An Introduction with R. Boca Raton, FL: Chapman Hall/ CRC.

Wyant BR (2008) Multilevel impacts of perceived incivilities and perceptions of crime risk on fear of crime isolating endogenous impacts. Journal of Research in Crime and Delinquency 45, 39-64.

Yen IH, Michael YL and Perdue L (2009) Neighborhood environment in studies of health of older adults: a systematic review. American Journal of Preventive Medicine 37, 455-463.

Cite this article: Köber G, Oberwittler D, Wickes R (2022). Old age and fear of crime: cross-national evidence for a decreased impact of neighbourhood disadvantage in older age. Ageing \& Society 42, 1629-1658. https://doi.org/10.1017/S0144686X20001683 